\title{
Calcretes pedogenéticos da Bacia de Itaboraí, Estado do Rio de Janeiro
}

\author{
Paula Braga ADLER ${ }^{1}$, Luiz Fernando DE ROS², Kátia Leite MANSUR ${ }^{1}$ \& André Luiz FERRARI ${ }^{3}$
}

1 Programa de Pós-graduação em Geologia, Universidade Federal do Rio de Janeiro. Av. Athos da Silveira, 274, CEP 21941916, Rio de Janeiro, RJ, Brasil (paulabragaadler@gmail.com, katia@geologia.ufrj.br).

2 Departamento de Mineralogia e Petrologia, Instituto de Geociências, Universidade Federal do Rio Grande do Sul. Av. Bento Gonçalves, 9500, CEP 91.540-000, Porto Alegre, RS, Brasil (lfderos@inf.ufrgs.br).

3 Departamento de Geologia e Geofísica, Universidade Federal Fluminense. Av. Litorânea s/no, Gragoatá, CEP 24210-340, Rio de Janeiro, RJ, Brasil (andreluizferrari@id.uff.br).

Recebido em 05/2016. Aceito para publicação em 07/2017.

Versão online publicada em 21/10/2017 (www.pesquisasemgeociencias.ufrgs.br)

\begin{abstract}
Resumo - A Bacia de Itaboraí é considerada o primeiro segmento do Rifte Continental do Sudeste do Brasil a se abrir, durante o Paleoceno. Há referências à existência de calcretes na bacia, entretanto, até o momento, não foram realizados estudos específicos sobre os calcretes e sobre sua ocorrência, e ainda há um número reduzido de trabalhos envolvendo a caracterização petrográfica dos depósitos sedimentares da bacia. Apresenta-se aqui uma caracterização, macromorfológica e micromorfológica dos calcretes vadosos que constituem o preenchimento inicial da bacia e que são encontrados nas suas bordas norte e oeste. Foram descritos e interpretados os aspectos composicionais, texturais e de fábrica de 27 seções delgadas preparadas de amostras de calcretes. Os calcretes pedogenéticos mostram diferentes fácies (pulverulento, nodular, maciço, placoso, laminar incipiente e brechado), que foram atribuídas a estágios morfogenéticos distintos. As principais feições micromorfológicas incluem: nódulos, gretas de contração, rizólitos, argilas infiltradas, grãos corroídos e fraturados, micas expandidas, e agregados argilosos. Os calcretes pedogenéticos se desenvolveram em depósitos aluviais intemperizados, em períodos de estabilidade tectônica e são característicos de ambientes continentais áridos a semiáridos. Ocorrem intercalados a travertinos, crostas carbonáticas de origem hidrotermal, cuja deposição é condicionada pela movimentação de falhas ativas e favorecida em períodos de clima úmido. Os resultados indicam que processos pedogenéticos e hidrotermais foram extremamente atuantes durante o início do preenchimento da Bacia de Itaboraí, e sua caracterização é importante para a compreensão da evolução inicial do Rift Continental do Sudeste do Brasil.

Palavras-chave: carbonatos terrestres, fácies pedogenéticas, pedogênese, micromorfologia.
\end{abstract}

Abstract - Pedogenetic calcretes from the Itaboraí Basin, Rio de Janeiro State, Brasil. The Itaboraí Basin, located in Rio de Janeiro State, Brazil, is considered the first segment from the Southeastern Brazil Continental Rift opened, during the Paleocene. The occurrence of calcretes was previously reported in the literature, although studies dealing specifically with such calcretes and their distribution were not performed. Furthermore, there is limited research involving the petrographic characterization of the sedimentary deposits of the basin. This study developed a characterization on both macro and micro scale of the vadose calcretes that occur along the northern and western margins of the basin and constitute its initial infilling. The compositional, textural and fabric features of 27 thin sections prepared from calcrete samples were described and interpreted. The pedogenetic calcretes were separated in different facies (chalky, nodular, massive, platy, incipient laminar and brecciated), and classified according to morphogenetic stages. The main microscopic features include nodules, contraction cracks, vadose pisoliths, rhizocretions, infiltrated clays, corroded grains, expanded micas and clay aggregates. The pedogenetic calcretes were developed on weathered alluvial deposits during tectonic stability periods. They are typically generated on continental environments under arid to semiarid climates and occur intercalated with travertines (carbonate crusts of hydrothermal origin), which deposition is favored by fault activity during humid climate periods. The results indicate both pedogenetic and hydrothermal processes have been extremely active and have played important role during the early evolution of Itaboraí Basin. Thus, the characterization of such processes is essential to the understanding of the initial evolution of Southeastern Brazil Continental Rift.

Keywords: terrestrial carbonates, pedogenetic facies, pedogenesis, micromorphology. 


\section{Introdução}

Calcretes ou caliches são um dos tipos de carbonatos continentais que receberam mais atenção de cientistas de diversas áreas, incluindo a geomorfologia, a pedologia e a sedimentologia (Alonso-Zarza, 2003; Alonso-Zarza \& Wright, 2010). Muitos autores estabeleceram metodologias para sua descrição, classificação e interpretação (Gile et al.1965, 1966; Esteban \& Klappa 1983; Bachman \& Machette, 1977; Machette 1985; Wright \& Tucker 1991; Alonso-Zarza 2003; Alonso-Zarza \& Wright 2010). Esse interesse resulta de sua ocorrência disseminada em ambientes continentais antigos e modernos sob condições áridas e semiáridas, e por constituírem fonte de importantes informações para reconstrução das condições paleoambientais em que foram formados (Alonso-Zarza \& Wright, 2010; Sacristán-Horcajada et al., 2016).

A Bacia de São José de Itaboraí, ou Bacia de Itaboraí, localizada no município homônimo do Estado do Rio de Janeiro, é a menor bacia componente do Rifte Continental do Sudeste do Brasil, sendo considerada o primeiro segmento deste a se abrir, durante o Paleoceno (Riccomini, 1989; Riccomini et al., 2004). A bacia é a única no contexto do Rifte que apresenta preenchimento carbonático expressivo (Rodrigues Francisco \& Cunha, 1978; Tibana et al., 1984) e foi explorada por mais de 50 anos para produção de cimento. Tornou-se conhecida no meio científico devido à sua notável riqueza fossilífera, que inclui gastrópodes, mamíferos, anfíbios, répteis, aves e vegetais (Rodrigues Francisco, 1989).

Referências à ocorrência pontual de calcretes na bacia são feitas por Tibana et al. (1984), Sant'Anna (1999) e Sant'Anna et al. (2004). No entanto, até o momento não foram realizados estudos especificamente sobre os calcretes da bacia. Em contraste, é reconhecida a significativa importância da percolação de fluidos hidrotermais através da borda de falha principal da bacia, originando travertinos (Leinz, 1938; Tibana et al., 1984; Ferrari, 2001; Sant'Anna et al., 2004). É também frequentemente mencionada a existência de intercalações de depósitos clásticos com os hidrotermais (Leinz, 1938; Rodrigues Francisco \& Cunha, 1978; Tibana et al., 1984, Brito, 1989; Medeiros \& Bergqvist, 1999).

Apesar da intensa extração do calcário ter removido boa parte das rochas da bacia, o estudo dos depósitos remanescentes permite que se acrescente importantes informações sobre sua gênese e evolução.

Este trabalho apresenta a caracterização dos calcretes pedogenéticos que constituem os depósitos remanescentes da bacia, em macro e microescala, buscando contribuir para a compreensão das condições paleoambientais associadas à sua evolução inicial.

\section{2 Área de estudo, materiais e métodos e terminologia}

\subsection{Localização e contexto geológico}

A Bacia de Itaboraí se localiza no município de Itaboraí, Estado do Rio de Janeiro, com coorde-

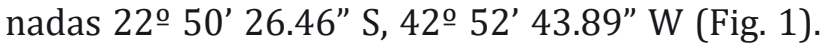
A bacia está inserida no Parque Paleontológico de São José de Itaboraí, que foi estabelecido em 1995 devido à sua notável riqueza fossilífera (Beltrão et al., 2001).

A bacia apresenta formato elíptico, com aproximadamente $1.500 \mathrm{~m}$ no semieixo maior, e $500 \mathrm{~m}$ no menor (Rodrigues Francisco \& Cunha, 1978; Tibana et al., 1984; Lima \& Cunha, 1986). Como registrado a partir de numerosas sondagens feitas na época da exploração, sua profundidade máxima atingia cerca de 100 m (Leinz, 1938; Rodrigues Francisco \& Cunha, 1978; Bergqvist et al., 2005).

A origem da Bacia de Itaboraí é vinculada à instalação do Rifte Continental do Sudeste do Brasil (Fig. 1), sendo considerada o primeiro segmento deste a se abrir durante o Paleoceno. Ferrari (2001), que realizou uma análise estrutural da bacia dentro do contexto de evolução do Graben da Guanabara, assume que sua abertura se deu em regime de transcorrência sinistral, que também foi responsável por sua deformação (geração da falha transversal, rotação e basculamento dos blocos a oeste e a leste desta e geração de estruturas compressivas). 0 autor ressalta que situações semelhantes, nas quais a evolução do rifte se inicia sob a atuação de um regime direcional, foram descritas nos riftes do leste africano, Baikal e na abertura do Oceano Atlântico Setentrional, e que esta implantação inicial de um regime direcional pode ser resposta às anisotropias mecânicas do manto subjacente.

Em trabalho pioneiro, Leinz (1938) descreveu três litotipos na bacia: "calcário puro fitado" (constituído por crostas de calcita de origem hidrotermal, pontualmente passando a calcário oolítico), "calcário cinzento" (composto por "além de calcita, numerosos minerais detríticos", localmente, rico em fósseis) e "sedimentos eluviais" (conglomerados constituídos por seixos arredondados). 


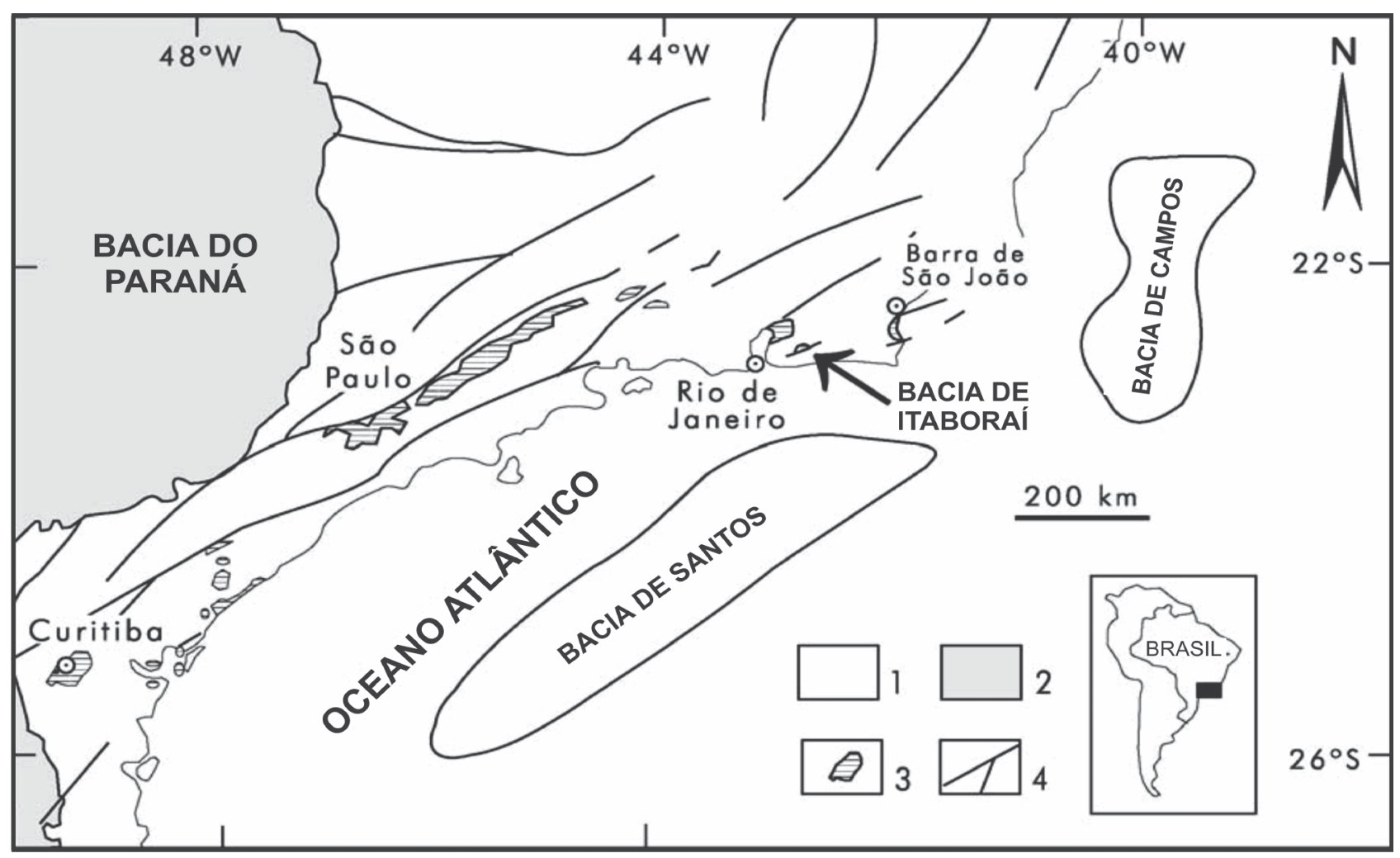

Figura 1. Contexto regional do Rifte Continental do Sudeste do Brasil e localização da Bacia de Itaboraí (traduzido de Sant'Anna et al., 2004). (1) Embasamento Pré-Cambriano; (2) Rochas vulcânicas e sedimentares paleozoicas e mesozoicas da Bacia do Paraná; (3) Depósitos sedimentares cenozoicos do Rifte Continental do Sudeste do Brasil; (4) Zonas de cisalhamento Pré-Cambrianas parcialmente reativadas no Mesozoico e no Cenozoico.

Figure 1. Regional context of the Southeastern Brazil Continental Rift and location of the Itaboraí basin (Sant'Anna et al., 2004). (1) Precambrian basement; (2) Paleozoic and Mesozoic sedimentary and volcanic rocks of the Paraná basin; (3) Cenozoic sedimentary deposits of the Southeastern Brazil Continental Rift; (4) Precambrian shear zones, partially reactivated in the Mesozoic and Cenozoic.

Desde o trabalho de Leinz, diversos outros estudos descritivos foram realizados na bacia (Brito et al., 1972; Palma \& Brito, 1974; Rodrigues Francisco \& Cunha, 1978; Tibana et al., 1984; Brito, 1989; Rodrigues Francisco, 1989; Medeiros \& Bergqvist, 1999; Sant'Anna, 1999; Klein \& Bergqvist, 2002; Sant'Anna et al., 2004), caracterizando seu preenchimento e endossando aquelas descrições pioneiras, apesar de algumas discordâncias, principalmente quanto às interpretações genéticas e à idade relativa das unidades sedimentares.

Apesar de haver diferenças quanto às designações, assim como a detalhes descritivos e interpretativos, o estudo e a compilação de diferentes trabalhos permitem a sistematização de quatro tipos litológicos principais na bacia.

Calcário travertino, calcário fitado ou crostas de calcita: são crostas cristalinas, de origem química, dispostas em camadas irregulares e lenticulares, ou sob a forma de veios que preenchem fraturas sub-horizontais e sub-verticais, que cortam o embasamento e rochas sedimentares da bacia (Ferrari, 2001; Sant'Anna et al., 2004). As camadas são compostas por agregados de cristais grossos e fibrorradiados de calcita, que são perpendiculares à superfície de deposição (Leinz, 1938; Tibana et al., 1984; Sant'Anna et al., 2004).

Calcário cinzento e calcário argiloso: essas designações são bastante comuns na bibliografia sobre a bacia e são potencialmente confusas. A elas são atribuídos variados significados, por diferentes autores e, às vezes, ambas são aplicadas em referência a mesma litologia. É comum o uso do termo calcário cinzento como referência a uma rocha de origem detrítica (Brito et al., 1972; Rodrigues Francisco \& Cunha, 1978; Medeiros \& Bergqvist, 1999; Klein \& Bergqvist, 2002; Bergqvist et al., 2005), formada por fluxos gravitacionais. Rodrigues Francisco \& Cunha (1978) o descrevem como uma rocha de granulometria grossa, constituída por "uma matriz fina de argila e calcita e por detritos de diversos minerais", incluindo grãos angulosos de quartzo, feldspatos, micas, granada e fragmentos de rochas. Esse calcário impuro cederia lugar, pontualmente, a uma "variedade pouco argilosa e a arenitos calcíferos". Diversos trabalhos fazem referência à gradação lateral de fácies detríticas constituídas por mistura, em diferentes proporções, de constituintes carbonáticos com grãos siliciclásticos. Assim como relatam a presença de 
fragmentos de gastrópodes, ostracodes, fragmentos vegetais e fragmentos de vertebrados nestas rochas (Leinz, 1938; Rodrigues Francisco \& Cunha, 1978; Tibana et al., 1984; Brito, 1989; Medeiros \& Bergqvist, 1999).

Calcário oolítico/pisolítico ou pérolas de caverna: ocorrem principalmente como lentes no travertino, mas também como bancos e sob forma disseminada no calcário argiloso (Rodrigues Francisco \& Cunha, 1978; Sant'Anna et al., 2004). As lentes de travertino pisolítico intercaladas nas crostas cristalinas são interpretadas como depositadas em pequenas piscinas, próximas às fontes hidrotermais. A laminação concêntrica dos pisolitos sugere que sua geração se deu sob fluxo aquoso turbulento (Folk \& Chafetz, 1983; Guo \& Riding, 1998; Sant'Anna et al., 2004).

Depósitos clásticos ricos em fósseis, preenchendo fissuras e cavidades de dissolução: canais de dissolução que cortam depósitos sedimentares mais antigos (intercalações de travertinos com calcário argiloso) (Brito et al., 1972; Rodrigues Francisco \& Cunha, 1978; Brito, 1989; Medeiros \& Bergqvist, 1999) e são preenchidos por argilas e margas "de coloração escura", com minerais detríticos e rica fauna de vertebrados, principalmente de mamíferos (Brito, 1989). Rodrigues Francisco (1989) os descreve como depósitos rudáceos, arenosos e argilosos, com restos de vertebrados.

Depósitos aluviais conglomeráticos pleistocênicos ocorrem capeando os sedimentos da bacia. Consistem em depósitos conglomeráticos que contêm fósseis de mamíferos e répteis (Price \& Campos, 1970; Brito et al., 1972; Rodrigues Francisco \& Cunha, 1978; Brito, 1989; Medeiros \& Bergqvist, 1999). Esses sedimentos rudáceos contêm matacões, calhaus e seixos, predominantemente angulosos, em matriz areno-argilosa (Rodrigues Francisco \& Cunha, 1978; Medeiros \& Bergqvist, 1999).

Tibana et al. (1984), Sant'Anna (1999) e Sant'Anna et al. (2004) fazem referência à ocorrência pontual de calcretes na bacia, descritos como constituídos por nódulos de carbonato microcristalino.

Medeiros \& Bergqvist (1999) agruparam litofácies em associações e estas, em sequências, as quais designaram como S1, S2 e S3. 0 mapa geológico e a coluna estratigráfica da Bacia de São José de Itaboraí segundo Bergqvist et al. (2005) mostram essa distinção (Fig. 2).

Intercaladas às rochas sedimentares paleogênicas da Bacia de São José de Itaboraí, ocorrem rochas ígneas ankaramíticas (Fig. 2), que foram identificadas primeiramente por Rodrigues Francisco et al. (1982) como um dique subvertical de orientação N45E (Klein \& Valença, 1984). Klein \& Valença (1984) notaram também a ocorrência de um derrame com pillow lavas e analisaram a rocha petrográfica e quimicamente. Riccomini \& Rodrigues Francisco (1992) realizaram uma determinação de idade K-Ar em rocha total, obtendo a idade de 52,6 \pm 2,4 Ma (Eoceno Inferior). Nova datação foi feita por Mota et al. (2015), pelo método Ar-Ar, conferindo 54,89 \pm 1,40 Ma ao ankaramito de Itaboraí. Não se exclui a possibilidade de vínculo das ocorrências da Bacia de São José de Itaboraí e de Volta Redonda a um mesmo evento magmático eocênico (Klein \& Valença, 1984; Sant'Anna \& Riccomini, 2001).

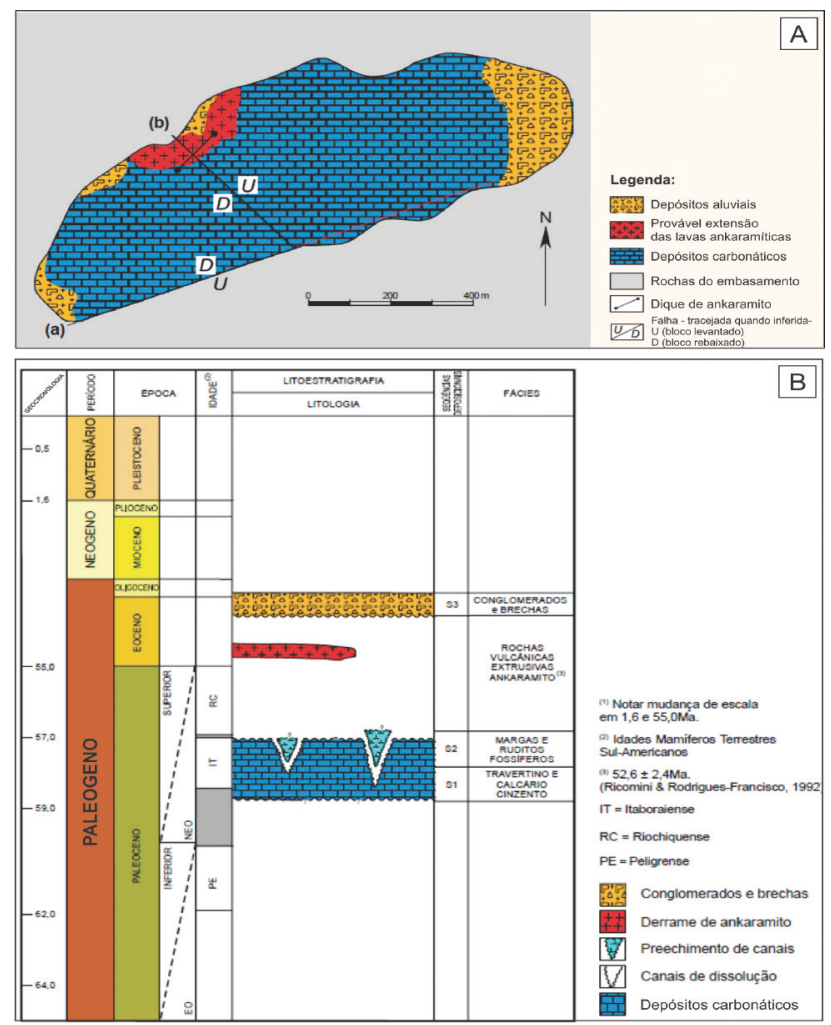

Figura 2. Mapa geológico e coluna estratigráfica da Bacia de Itaboraí, modificados de Bergqvist et al. (2005). A) Mapa geológico: (a) Falha São José; (b) Falha Transversal; B) Coluna estratigráfica da bacia.

Figure 2. Geological map and stratigraphic column of the Itaboraí basin, both modified from Bergqvist et al. (2005). A) Geological map: (a) São José Fault; (b) Transversal Fault; B) Stratigraphic column of the basin.

A sucessão inicial de sedimentos clásticos é descrita por diversos autores (Leinz, 1938; Rodrigues Francisco \& Cunha, 1978; Tibana et al., 1984, Brito, 1989; Medeiros \& Bergqvist, 1999) e relacionada a fluxos gravitacionais em um lago tectônico raso. Nesse contexto lacustre, os travertinos seriam originados de fontes carbonáticas hidrotermais, situadas ao longo da Falha de São José, na borda sul, a partir de fluidos enriquecidos em carbonato de cálcio devido à interação com lentes de mármo- 
re presentes no embasamento Pré-Cambriano. Os períodos de maior fluxo dos fluidos corresponderiam a ciclos de movimentação da referida falha (Medeiros \& Bergqvist, 1999). Soerguimentos relativos do embasamento adjacente (área-fonte de sedimentos), associados a movimentações tectônicas, aumentariam o influxo de detritos para dentro da bacia. Essa dinâmica explicaria a alternância de períodos com maior aporte de sedimentos clásticos com aqueles de fluxo de soluções carbonáticas, produzindo os travertinos. Ferrari (2001) reitera a relação entre o hidrotermalismo e o tectonismo na bacia, tendo encontrado duas famílias de veios preenchidos por calcário travertino.

\subsection{Materiais e métodos}

Este trabalho faz parte de um estudo de detalhe da bacia, que inclui: levantamento e descrição de afloramentos de depósitos sedimentares remanescentes à exploração, com a confecção de um mapa de pontos (Fig. 3); a elaboração de perfis e seções de afloramentos (nos pontos 1, 2, 3, e 13); e, a descrição de um testemunho de sondagem (borda oeste). No mapa de pontos, estão localizados os afloramentos e o local da obtenção do testemunho.

Neste artigo, é apresentada uma caracterização dos calcretes pedogenéticos descritos e sua contextualização no testemunho de sondagem. Dentre os perfis e seções levantados, este foi escolhido para ser apresentado por abarcar a maior variedade de tipos de calcretes e oferecer um panorama geral de sua forma de ocorrência. Os perfis e seções de afloramentos podem ser consultados em Adler (2016).

Nesse testemunho, além das fácies de calcretes pedogenéticos, foram descritas fácies de calcrete freático e de calcretes pedogenéticos afetados por ação de fluidos hidrotermais, travertinos e travertinos afetados por processos pedogenéticos, que não serão abordadas neste artigo. A caracterização dos calcretes pedogenéticos foi determinada como foco deste devido à riqueza de informações que sua análise pode oferecer.

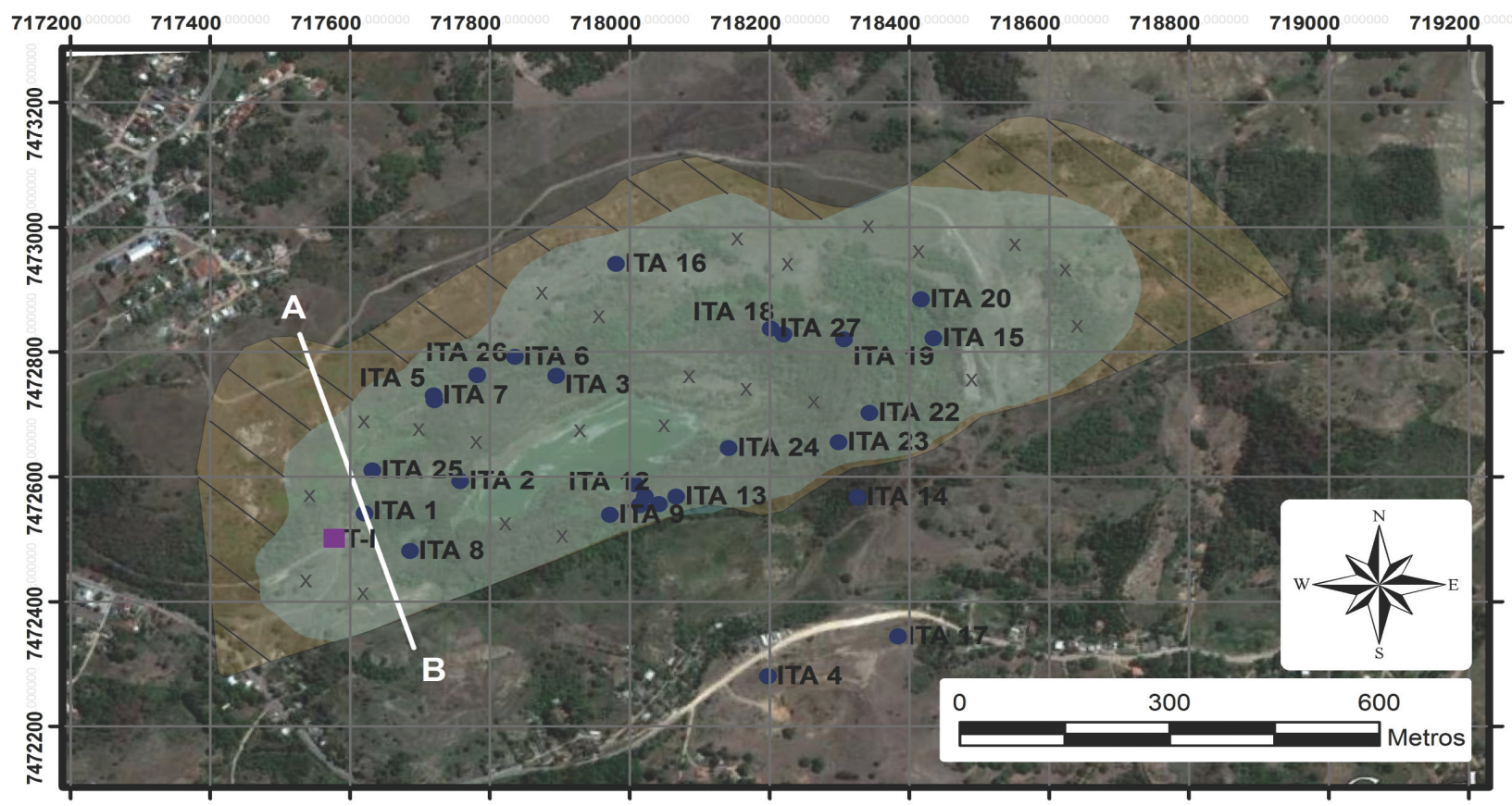

Figura 3. Locais de descrição de afloramentos e limites da Bacia de Itaboraí: a região demarcada com "x" corresponde aos limites segundo a Companhia Nacional de Cimento Portland Mauá (1965) e, a identificada com retas paralelas, como proposto por Ferrari (2001). 0 quadrado destaca o local de retirada do testemunho. Os calcretes pedogenéticos analisados foram descritos nos pontos 2, 3, 6 e 26 e no testemunho de sondagem. A linha AB mostra localização aproximada de uma seção através da bacia, extraída de Ferrari (2001). Coordenadas em UTM. Imagem base obtida no Google Earth, em 13/06/15.

Figure 3. Location of outcrops described during the research and Itaboraí Basin boundaries: highlighted and identified with ' $x$ ', as determined by Companhia Nacional de Cimento Portland Mauá (1965) and marked with parallel lines, by Ferrari (2001). The analyzed pedogenetic calcretes were described at points 2, 3, 6 and 26 and on the borehole (drilling location at purple square). AB line represents a section across the basin, which is presented in Figure 4. Coordinate system: UTM. Image obtained from Google Earth on 06/13/15.

As rochas descritas foram separadas segundo seus aspectos estruturais, texturais, composicionais e de fábrica. A separação, descrição e interpretação genética dos diferentes tipos litológicos e das fácies de calcretes só foi possível a partir da integração dos dados de petrografia com descrições macroscópicas e relações de campo, de forma a potencializar as descrições realizadas nas escalas 
macroscópica e microscópica.

Para classificar a morfologia dos calcretes e designar as fácies, foi aplicada a terminologia desenvolvida por Gile et al. (1966), modificada e revisada por diversos autores (Bachman \& Ma- chette, 1977; Machette, 1985; Alonso-Zarza, 2003; Wright, 2007). Os estágios de desenvolvimento dos calcretes pedogenéticos foram interpretados segundo Machette (1985) e Alonso-Zarza (2003).

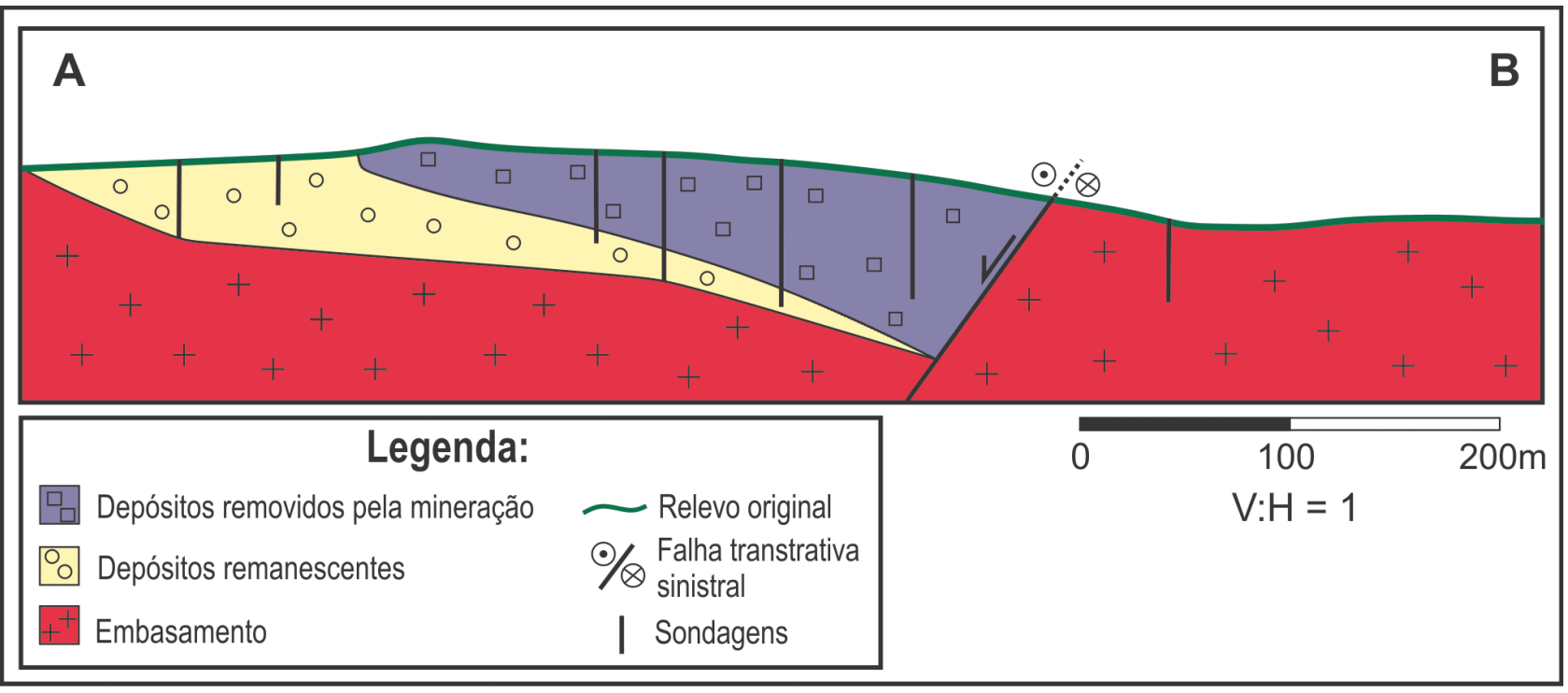

Figura 4. Seção esquemática transversal à bacia (vide Fig. 3), modificada de Ferrari (2001). As sondagens indicadas foram feitas pela Companhia Nacional de Cimento Portland Mauá (1965) na época da mineração. Na seção estão representados os depósitos removidos pela mineração e aqueles que foram deixados por não despertarem interesse econômico.

Figure 4. Schematic section across the Itaboraí Basin, modified from Ferrari (2001). Boreholes were drilled by Companhia Nacional de Cimento Portland Mauá (1965), during limestone exploration activity. Both the deposits mined for cement production and those not removed are represented.

As 27 lâminas analisadas foram preparadas a partir de amostras coletadas ao longo dos perfis de afloramentos e do testemunho, que foi retirado em 2011, aproximadamente duas décadas depois da atividade de mineração ter sido encerrada. Desta forma, tanto as amostras dos afloramentos como as do testemunho são representativas dos depósitos basais, dispostos sobre o embasamento, que são remanescentes da exploração da bacia (Fig. 4).

Para a preparação das lâminas, as amostras passaram por impregnação a vácuo, com resina azul, e por polimento, no laboratório de laminação da Universidade Federal do Rio de Janeiro.

Ao microscópio, foram observados os aspectos composicionais e micromorfológicos das rochas descritas, que foram interpretados e integrados. Para possibilitar a distinção dos carbonatos, as lâminas foram tingidas com solução de alizarina e ferricianeto de potássio.

As classes de tamanhos de cristais usadas nas descrições apresentadas nesse trabalho são designadas e aplicadas de acordo com Hallsworth \& Knox (1999). 0 termo "microcristalino" é usado como referência a tamanhos entre 0,004 e 0,062 $\mathrm{mm}$.

Devido à recuperação muito baixa do testemunho (Luna, 2012; Luna et al., 2012), adotou-se o critério de situar os intervalos não recuperados na base de cada intervalo de profundidade, indicada no eixo vertical do perfil. Os intervalos não recuperados são representados com um comprimento fixo no perfil, apesar de, na realidade, representarem espessuras variadas. Este mecanismo foi adotado para reduzir o tamanho de representação do perfil, a fim de tornar mais objetiva sua observação, que se tornou possível em uma única folha.

A escala apresentada ao lado do perfil pode ser usada para calcular a espessura real dos intervalos representados. Pelos motivos esclarecidos, a apresentação do perfil do testemunho tornou-se ligeiramente esquemática sem, no entanto, comprometer a variedade e a precisão das informações que a sua análise fornece.

\subsection{Terminologia}

Diferenças de terminologia são comuns entre os pesquisadores que estudam calcretes, principalmente se comparando as áreas de sedimentologia e pedologia, e especificamente no estudo dos calcretes pedogenéticos (Dal' Bó et al., 2009).

Diversas definições de calcretes foram propostas, sobretudo no que concerne às suas variedades pedogenéticas (Gile, 1966; Netterberg, 1969; Goudie, 1973, 1983; Watts, 1980; Machette, 
1985).

Neste trabalho, calcrete é utilizado no senso de Wright \& Tucker (1991, p. 01), que inclui tanto os calcretes de origem pedogenética como os de origem freática: calcretes são acumulações de carbonato de cálcio (principalmente calcita), formadas próximas à superfície em ambientes terrestres, que ocorrem sob uma variedade de formas, incluindo tipos pulverulento a nodular, maciço e laminado. Esses são resultantes de cimentação, deslocamento e substituição de perfis de solo, sedimentos e diferentes substratos rochosos por calcita, em áreas onde as águas subterrâneas da zona vadosa e/ou freática estão saturadas em carbonato de cálcio.

Considerando a evolução dos calcretes pedogenéticos, Gile et al. (1966) propuseram que diferentes características morfológicas de calcretes pedogenéticos poderiam ser interpretadas como diferentes estágios morfológicos, que refletem o grau de desenvolvimento dos calcretes. Posteriormente, foram idealizados diversos perfis de calcretes, compostos por horizontes que são caracterizados e distinguidos com base nas feições morfológicas mais proeminentes (Esteban \& Klappa, 1983; Machette 1985; Alonso-Zarza et al. 1998; Alonso-Zarza 2003; Alonso-Zarza \& Wright 2010).

Neste trabalho, a exemplo de Sacristán-Horcajada et al. (2016), o termo fácies pedogenética é preferido ao termo horizonte, já que os depósitos estudados representam a superimposição de diversos estágios de desenvolvimento, além de apresentarem evidências de modificações por processos que não são pedogenéticos (modificações estas que não são abordadas no presente artigo). Por esse motivo, o termo horizonte, que tem implicações tanto morfológicas como genéticas, não foi considerado apropriado.

É comum que termos da pedologia sejam utilizados na descrição microscópica dos calcretes pedogenéticos, em designação a elementos estruturais do solo: peds (agregados de solo), cutans (superfícies modificadas de peds, clastos ou cristais), glébulas (glaebules, ex.: nódulos e concreções), cristais (podem engolfar grãos de solo), pedotúbulos (principalmente bioturbações e marcas de raízes), plasma (porção fina do solo) (Retallack, 2001).

Diversas propostas e revisões de esquemas de descrição e de classificação micromorfológica de solos foram publicadas (Kubiena, 1938; Brewer, 1976; FitzPatrick, 1984; Bullock et al., 1985; Retallack, 2001; De Castro, 2008; Fedoroff et al., 2010). Neste trabalho, os conceitos pedológicos utilizados são aplicados segundo Brewer (1976).

\section{Resultados}

\subsection{Fácies de calcretes pedogenéticos}

Com base na terminologia de Gile et al. (1966) - revisada e modificada por diversos autores (Bachman \& Machette, 1977; Machette, 1985; Alonso-Zarza, 2003; Wright, 2007) - e na integração das descrições macroscópicas e microscópicas, foram distinguidas seis fácies de calcretes pedogenéticos nos depósitos remanescentes da Bacia de Itaboraí: pulverulentas $(\mathrm{P})$, nodulares $(\mathrm{N})$, maciças $(\mathrm{M})$, placosas (Pl), laminares incipirentes (Li) e brechadas (B).

Estas diferem quanto aspectos estruturais, texturais, composicionais e de fábrica. Em consonância com Gile et al. (1966), Machette (1985) e Alonso-Zarza (2003), em geral, as fácies associadas a um estágio mais avançado de desenvolvimento apresentam maior teor de carbonato.

Os calcretes pedogenéticos se desenvolveram em sedimentos arenosos a conglomeráticos, texturalmente imaturos, compostos por quartzo, feldspatos, fragmentos de rochas plutônicas de composição granítica, biotita, muscovita e, raramente, granada. Em alguns deles são descritos agregados de argilominerais pedogenéticos entre os grãos, que revelam o desenvolvimento de solos nesses sedimentos antes da formação dos calcretes.

Na maior parte dos calcretes é impossível observar qualquer característica deposicional, a não ser a imaturidade textural e a composição dos grãos detríticos. Grande parte das estruturas observadas nessas rochas é pedogenética, relacionada à formação dos calcretes e superimposta às estruturas sedimentares primárias.

As características macroscópicas preponderantes das fácies são apresentadas pelas fotomicrografias da figura 5. A ocorrência destas fácies é representada no perfil do testemunho (Fig. 6) e também foi registrada em afloramentos nas bordas oeste e norte da bacia (Fig. 7). As fácies pedogenéticas apresentam características micromorfológicas em comum, que são descritas na sessão 3.2. As fácies de calcretes freáticos, calcretes pedogenéticos afetados por fluidos hidrotermais, travertinos e travertinos afetados por pedogênese, que ocorrem intercaladas aos calcretes pedogenéticos no perfil do testemunho, não são tratadas nesse artigo.

Os calcretes pulverulentos (P) são constituídos por grãos detríticos texturalmente imaturos, herdados do material hospedeiro, "imersos" em material carbonático e argiloso de cor verde (cor Munsell (1991): 5GY 6/1, cinza esverdeado), de textura 
fina. Este material é distinguido no microscópio como agregados de argilominerais nos quais ocorre a precipitação de calcita, de forma disseminada ou como nódulos (ver sessão 3.2). Nas amostras de mão, de forma esparsa, há porções com maior concentração de carbonato, constituindo nódulos disformes com limites difusos, de tamanhos variados, que localmente se coalescem.
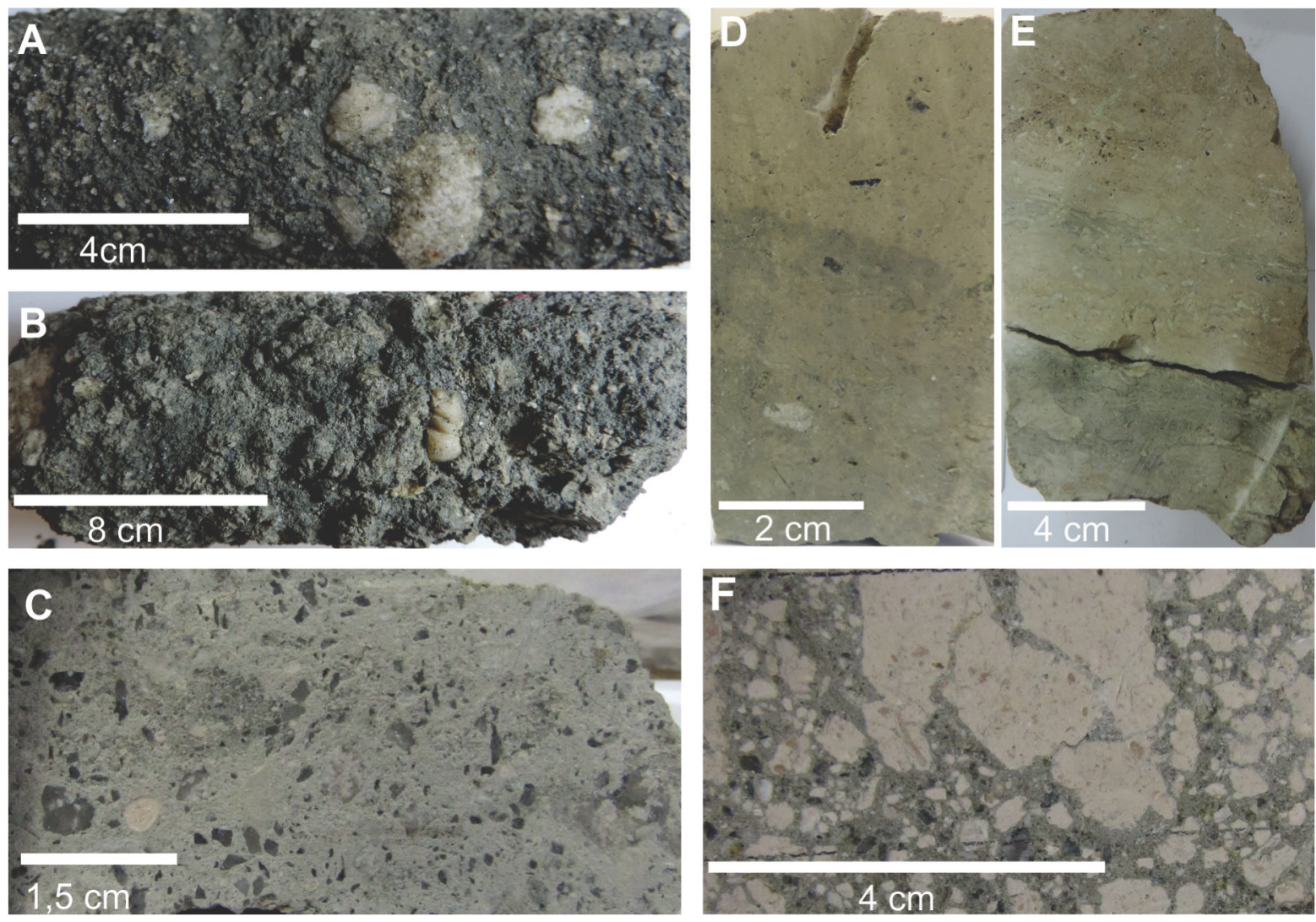

Figura 5. Aspectos macromorfológicos preponderantes nas diferentes fácies de calcretes pedogenéticos da Bacia de Itaboraí. A) Calcrete pulverulento constituído por grãos detríticos reliquiares "imersos" em carbonato e argilominerais (detalhes na sessão 3.2); B) Calcrete nodular texturalmente semelhante ao pulverulento apresentado na fotomicrografia A, mas que mostra uma maior concentração de carbonato, que se traduz como uma maior quantidade de nódulos que se coalescem; C) Calcrete maciço, em que grãos detríticos texturalmente imaturos (herdados) foram cimentados e deslocados pela precipitação de carbonato; D) Calcrete placoso, mostrando estrutura laminar de espessura centimétrica; E) Calcrete laminar incipiente, cuja laminação de espessura milimétrica é irregular e mal desenvolvida; F) Calcrete brechado, em que crosta carbonática (i.e. hardpan), com estrutura nodular a maciça apresenta-se fraturada e recimentada junto com os grãos detríticos que preenchem as fraturas. Figure 5. Proeminent morphological features on Itaboraí Basin's pedogenetic calcretes. A) Powdery calcrete containing pedogenetic matrix made of calcite and clay minerals (for details see session 3.2); B) Nodular calcrete texturally similar to the powdery showed on photomicrography A, but presenting a higher calcite concentration, which is seemed through numerous coalescent carbonate nodules; C) Massive calcrete, in which texturally immature inherited detritic grains were cimented and displaced by carbonate precipitation; D) Platy calcrete, depicting centimetric laminar estructure; E) Incipient laminar calcrete which milimetric lamination is irregular and badly evolved; F) Brecciated calcrete made of fractured carbonate crust (hardpan) that has nodular to massive structure which is recemented together with detrital grains that infill fractures.

Os calcretes maciços (M) consistem em carbonato fino maciço (constituído por agregados de nódulos coalescidos), no qual se encontram imersas proporções variáveis de grãos detríticos herdados (25-60\%), dispostos de forma caótica; apresentam cor Munsell (1991) N8 - cinza muito claro - a 5Y $6 / 1$ ou 5 B 7/1, cinza claro esverdeado ou azulado.

Os calcretes placosos (PI) apresentam estrutura laminar de espessura centimétrica, conferida por diferenças de cor ou de estrutura interna en- tre as lâminas. Associada a esta, são constatadas estruturas nodulares, brechadas e de raízes. Cavidades tubulares de raízes, com espessura menor que $5 \mathrm{~mm}$, preenchidas por carbonato fino de cor cinza, são observadas nas faces cortadas das amostras. Grãos detríticos herdados representam menos que $20 \%$ da rocha. Apresentam cores de Munsell (1991) 5YR 8/1 (cinza rosado) a 5B 7/1 (cinza claro azulado) ou N8 (cinza muito claro).

Os calcretes laminares incipientes (Li) apre- 
sentam estrutura laminar irregular, mal desenvolvida, de espessura milimétrica, conferida por diferenças de cor entre as lâminas. As lâminas são sub-horizontais, irregulares e, em geral, mais delgadas que $1 \mathrm{~mm}$. No topo do horizonte laminar, são observados pisolitos vadosos incipientes (fragmentos da crosta carbonática, tamanho areia a seixo, arredondados, fraturados in situ, envolvidos por cutículas carbonáticas e recimentados). A estrutura laminar e os pisolitos vadosos incipientes, que apenas podem ser observados em amostras cortadas, ocorrem associados a estruturas nodulares, brechadas e a feições tubulares de raízes. Ao microscópio, são observadas abundantes gretas de contração plano-paralelas e moldes de raízes sub-horizontais (descritos na sessão 3.2). Grãos detríticos reliquiares do material hospedeiro representam menos que $10 \%$ e em média $5 \%$ do volume da rocha. A cor Munsell (1991) varia de 5YR 8/1 a N7 - cinza rosado a cinza claro, ou é branca (N9).

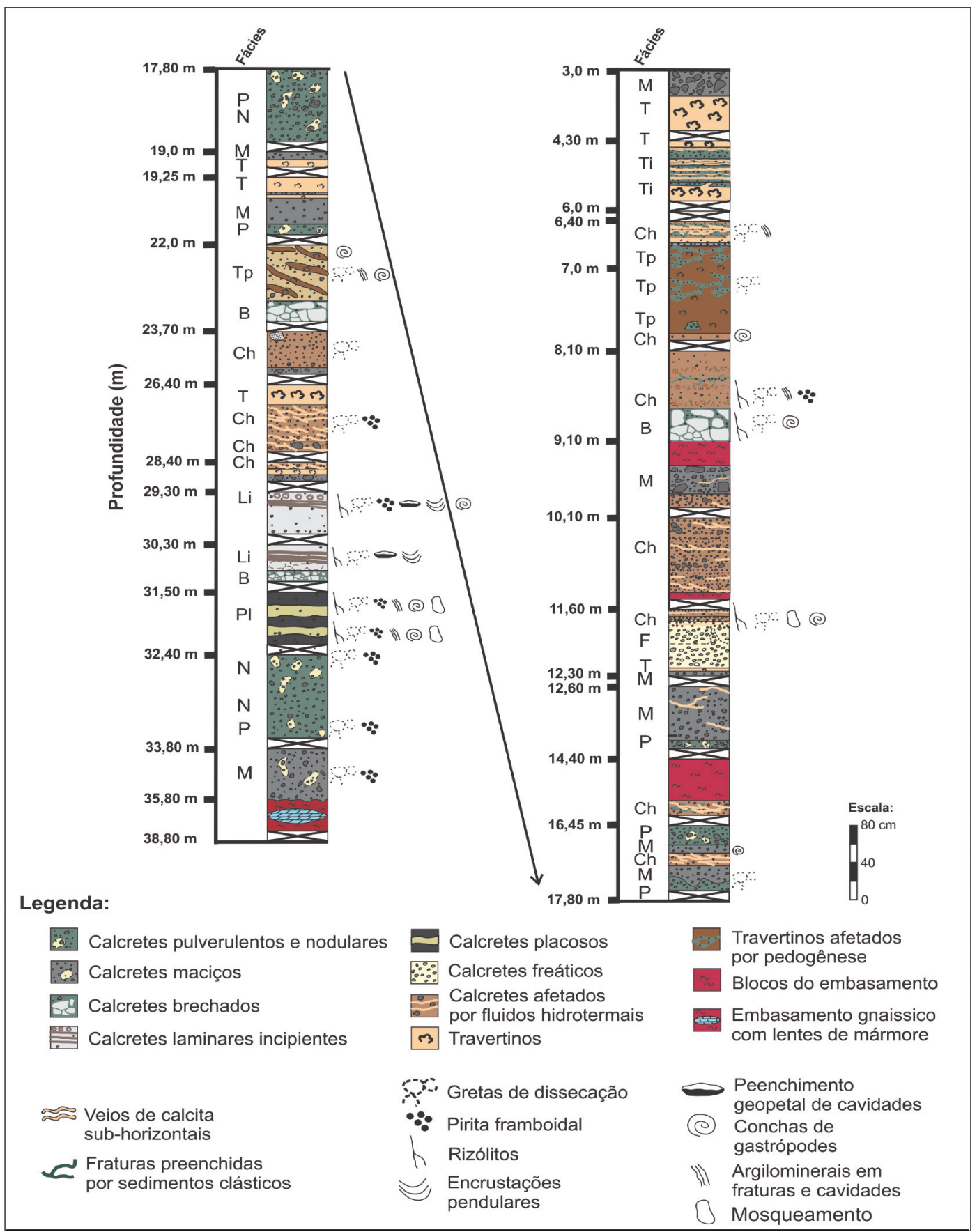

Figura 6. Perfis do testemunho de sondagem (borda oeste da bacia).

Figure 6. Sequential log of well cored at the western boundary of the basin.

A característica mais peculiar dos calcretes brechados (B) é a existência de abundantes fraturas afetando uma crosta formada por carbonato fino nodular a maciço, o que pode ser observado em escala macroscópica e microscópica. Em escala macroscópica, observa-se preenchimento das fra- 
turas por material detrítico e/ou carbonático. Os fragmentos "brechados" são irregulares ou arre-

dondados, de tamanhos variáveis, milímetros até centímetros.
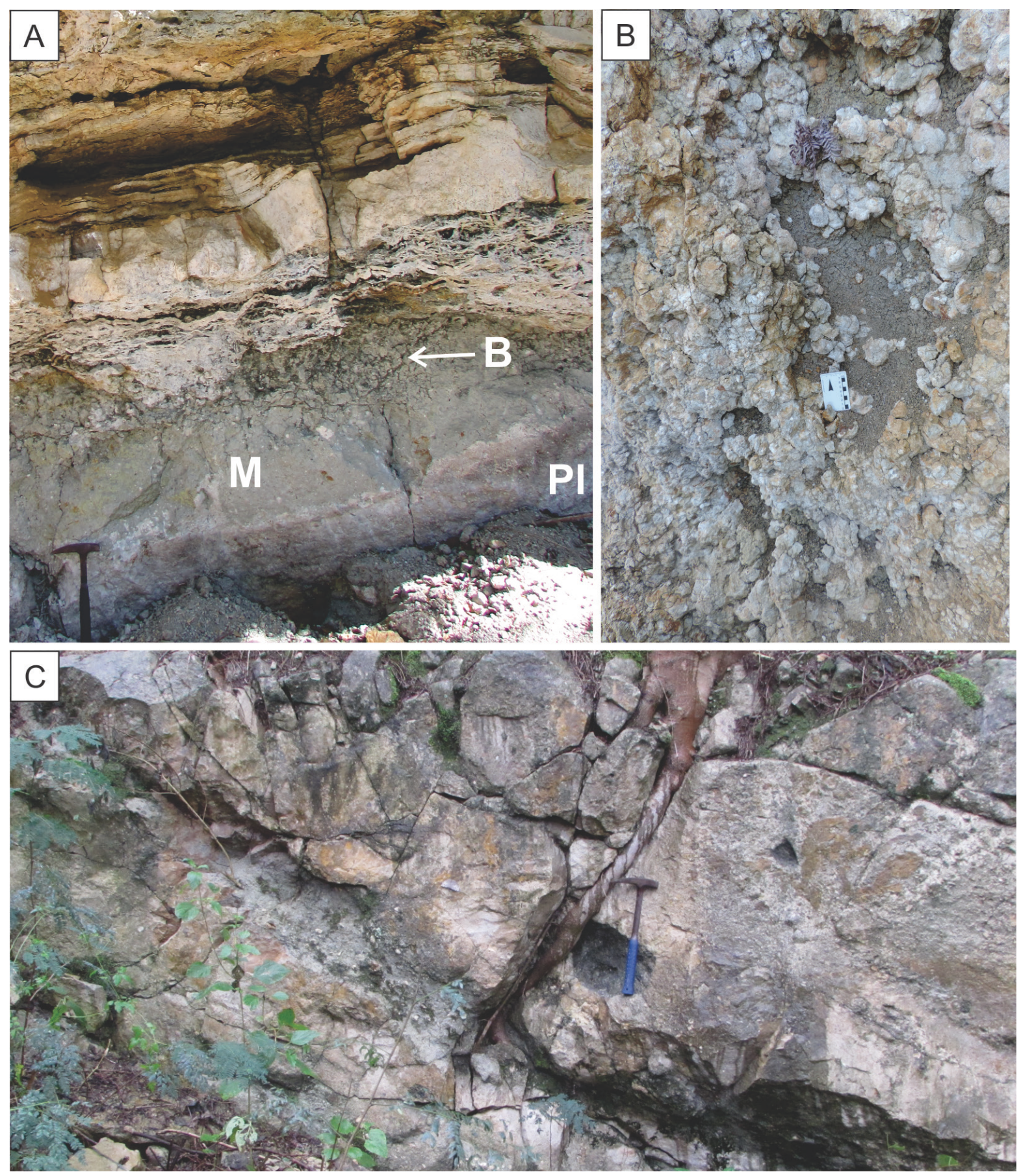

Figura 7. Calcretes pedogenéticos em afloramentos da borda oeste e norte. A) Calcretes placosos (Pl), maciços (M) e brechados (B) sotopostos a travertinos (ponto 2; Fig. 3); B) Calcrete nodular composto por nódulos arredondados coalescidos. Localmente, há lama siliciclástica entre os nódulos (ponto 6, Fig. 3); C) Calcretes maciços desenvolvidos em depósitos arenosos a conglomeráticos, texturalmente imaturos, dispostos em camadas lenticulares ou sigmoidais (ponto 3; Fig. 3).

Figure 7. Pedogenetic calcretes on outcrops at western and northern boundaries. A) Platy (Pl), massive (M) and brecciated (B) calcretes under travertines (point 2; Fig. 3); B) Nodular calcrete made by rounded and coalescent nodules. Locally, there are siliciclastic silt and clay between nodules (ponto 6; Fig. 3); C) Massive calcretes precipitated within texturally immature sandy to conglomeratic deposits organized in lenticular to sigmoidal layers (point 3; Fig. 3).

\subsection{Feições micromorfológicas}

Os calcretes descritos na Bacia de Itaboraí mostram uma variedade de feições micromorfológicas típicas de acumulações carbonáticas de origem pedogenética. Muitas destas feições são comuns a diversas fácies de calcretes e têm sua ocorrência indicada no perfil do testemunho (Fig. 6). Aqueles intervalos que não exibem esta representação das feições micromorfológicas não foram amostrados em seções delgadas, mas analisados quanto aos aspectos macromorfológicos. 
Nos calcretes pulverulentos e em alguns dos nodulares, são observados argilominerais pedogenéticos, com microfábrica plásmica bimassépica (i.e. orientados em duas direções aproximadamente perpendiculares entre si), esquelsépica (i.e. contornando grãos detríticos), argilassépica (i.e. argilominerais com baixa birrefringência) ou calciassépica (i.e. "mistura" de argilominerais de baixa birrefringência com carbonato microcristalino ou criptocristalino), ocorrem entre os grãos detríticos esqueletais (termos sensu Brewer, 1976; Fig. 8). Os argilominerais são localizadamente engolfados e substituídos por calcita e podem estar afetados por gretas de contração. De forma mais restrita, os argilominerais ocorrem como cutans em torno dos grãos (ie. cutículas; Fig. 8B), apresentando "laminações" formadas por consecutivas adições de material à superfície dos grãos. Nas outras fácies de calcretes, sua ocorrência é rara e constatada apenas pela existência de "fantasmas", estando intensamente substituídos por calcita.

Diversas amostras contêm pirita cúbica $a$ framboidal dispersa na calcita criptocristalina ou nos agregados de argilominerais (Fig. 8D).

Nódulos constituídos por calcita microcristalina ou criptocristalina são comuns em todos os tipos de calcretes. Os nódulos observados nos calcretes nodulares descritos afloramento do ponto 6 (Fig. 7B) são centimétricos, constituídos por calcita criptocristalina (Fig. 9A) ou microcristalina (Fig. 9B) e apresentam gretas de contração irregulares, radiais ou radiais paralelas, preenchidas por calcita de cristalinidade mais grossa. Localizadamente, observa-se dissolução intercristalina na calcita que preenche as fraturas (Fig. 9A). Entre os nódulos, nas bordas destes, localizadamente há uma franja de cristais prismáticos ou fibrosos (Fig. 9B).
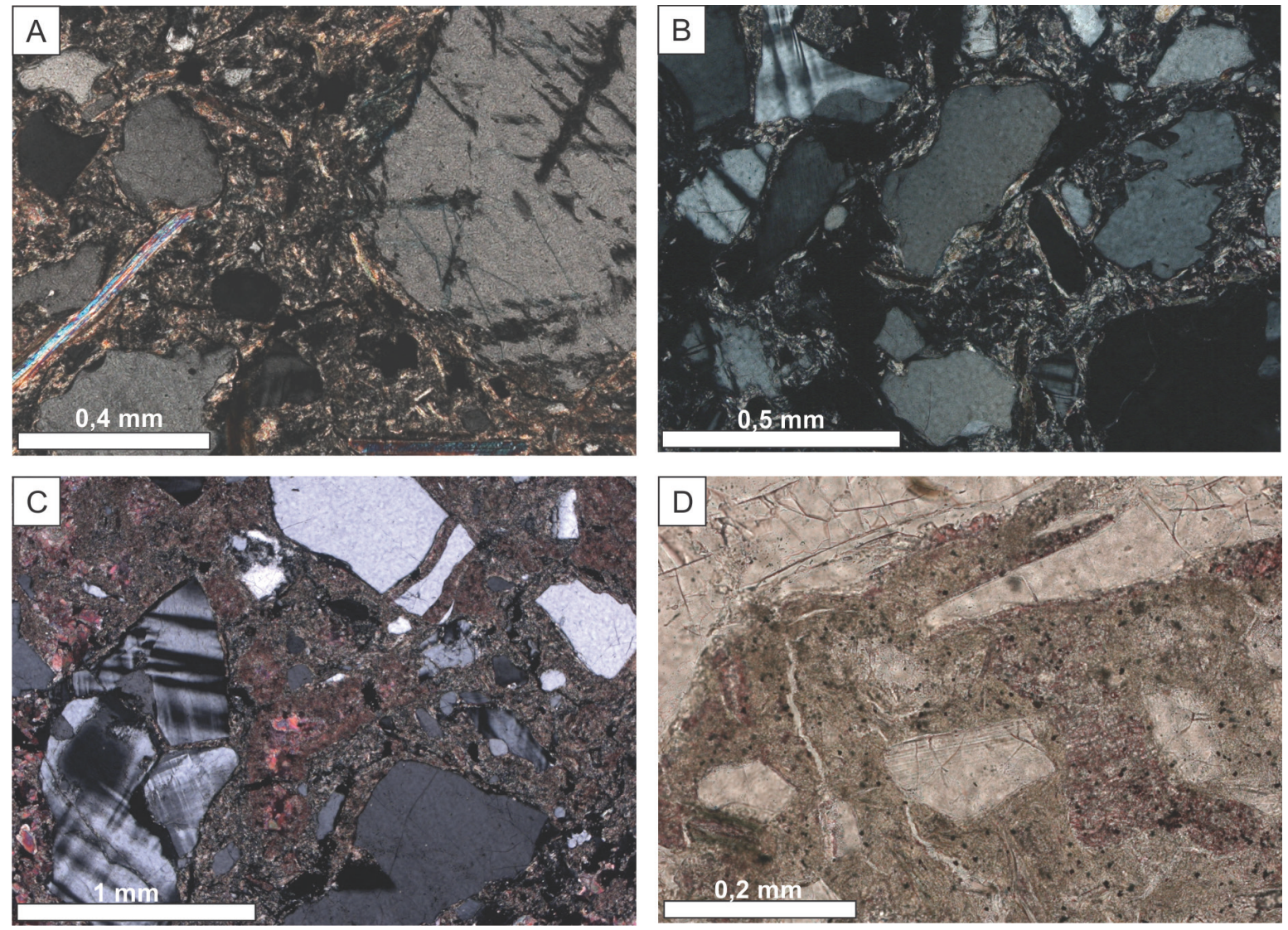

Figura 8. Argilominerais nos calcretes. A) Com microfábrica esquelsépica (XP); B) Como cutans em torno de grãos detríticos, (XP); C) "Núcleos" de precipitação de calcita (tingida de rosa) em meio aos agregados de argilominerais, (XP); D) Substituição parcial de argilominerais por pirita framboidal e por calcita criptocristalina (microfábrica calciassépica sensu Brewer, 1976), $(/ / \mathrm{P})$.

Figure 8. Clay minerals in calcretes. A) Showing bimasepic fabric, occupying intergranular space, (XP); B) As cutans surrounding grains, (XP); C) Calcite nodules (stained in pink) precipitation within clay mineral aggregates (calciasepic microfabric sensu Brewer 1976), (XP); D) clay minerals are partially replaced by framboidal pyrite and cryptocrystalline calcite, (//P).

Nas fácies de calcretes nodulares, maciços, placosos, laminares e brechados, abundante calcita criptocristalina ou microcristalina, constituindo nódulos e agregados maciços formados por nódu- los coalescidos, cimenta e desloca grãos siliciclásticos herdados do material hospedeiro, que parecem "flutuar" no carbonato (Fig. 10A, e 10C). 
Nos calcretes, frequentemente, observa-se fraturamento dos grãos (Fig. 8C, 10B) e expansão das micas por precipitação de calcita entre as clivagens (Fig. 10).

Gretas de contração circungranulares ocorrem em torno de grãos (Fig. 10C) ou de nódulos de calcita criptocristalina a microcristalina (Fig. $11 \mathrm{~A}$ e 11B), que concedem aspecto nodular/glaebular à rocha. Gretas plano-paralelas subhorizontais (Fig. 11D), poligonais (Fig. 11A) ou irregulares cortam agregados maciços formados por nódulos de calcita criptocristalina coalescidos.

Rizólitos ocorrem principalmente como cavidades tubulares (vistas em seções transversais, oblíquas ou longitudinais), que podem apresentar encrustações por calcita criptocristalina (rizocreções; Fig. 11D e E) e, em geral, são preenchidas por calcita microcristalina, mosaicos de calcita ou calcita drusiforme. De forma restrita, os rizólitos ocorrem como raízes permineralizadas, com impregnação do tecido celular, mas sem calcificação intracelular. Ocorrem em todas as fácies, com exceção das puverulentas, no entanto, são feições mais expressivas nos calcretes laminares.

Em alguns intervalos é observado preenchimento geopetal de cavidades, configurado pelo preenchimento parcial de moldes de raízes e de cavidades vugulares por silte vadoso (Fig. 10D) e de fraturas por argilominerais infiltrados (Fig. 11C).

Mosqueamento, devido a variações da concentração de produtos ferrosos no carbonato pedogenético, é visível em escala macroscópica e microscópica. Em escala microscópica ocorre como óxidos-hidróxidos de ferro que substituem localizadamente nódulos de calcita criptocristalina (Fig. 11B).

Nos calcretes podem ser encontrados fósseis de gastrópodes, que são abundantes em alguns in- tervalos. Eles podem estar bem preservados (Fig. $11 \mathrm{~F}$ ) ou fragmentados. Eventualmente, são completamente dissolvidos e a cavidade é preenchida por calcita drusiforme.

\section{Discussão}

Nas rochas estudadas foram observadas feições micromorfológicas que são consideradas por diversos autores como típicas de calcretes pedogenéticos: calcita criptocristalina a microcristalina cimentando e deslocando grãos detríticos ("grãos flutuantes"; Goudie, 1983; Wright \& Tucker, 1991; Alonso-Zarza, 2003); expansão e fraturamento de grãos (Buczynski \& Chafetz, 1987; Wright \& Tucker, 1991; Alonso-Zarza, 2003); gretas circungranulares em torno dos grãos detríticos (Wright \& Tucker, 1991; Alonso-Zarza, 2003); gretas de diversas geometrias cortando calcita criptocristalina (Alonso-Zarza \& Wright, 2010); rizocreções (Klappa, 1980a; Esteban \& Klappa, 1983; Wright \& Tucker, 1991); e, argilominerais pedogenéticos (Retallack, 2001), incluindo cutans de argila (Fedoroff, 1997; Esteban \& Klappa, 1983; Retallack, 2001; Fedoroff et al., 2010).

A introdução do carbonato de cálcio em perfis de solo, geralmente, ocorre de cima para baixo (Bachman \& Machette, 1977; Wright 2007), o que com o decorrer do tempo de estabilidade e da evolução dos perfis, leva à geração de zonas com maior concentração de carbonato de cálcio nas porções superiores (Bachman \& Machette, 1977; Alonso-Zarza, 1999). O desenvolvimento do processo origina crostas duras (Gile et al., 1966; Wright, 2007), que frequentemente apresentam abundantes marcas de raízes, laminações milimétricas ou centimétricas e fraturas geradas in situ (Esteban \& Klappa, 1983; Alonso-Zarza, 2003; Alonso-Zarza \& Wright,
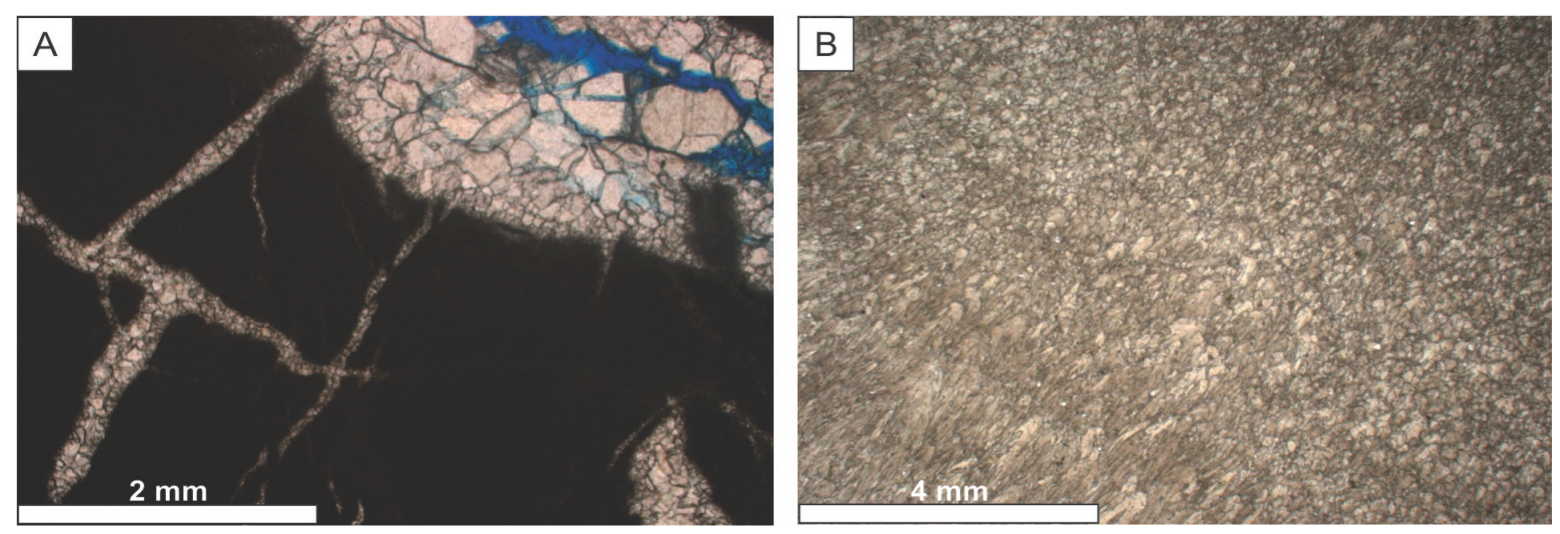

Figura 9. Detalhes de nódulos constituídos por calcita criptocristalina (A) ou microcristalina, locallizadamente fibrosa (B), (//P). Fraturas de contração são preenchidas por calcita microcristalina a drusiforme (A).

Figure 9. Detail of nodules made of cryptocrystalline calcite (A) or microcrystalline to fibrous calcite (B), (//P). Desiccation cracks are filled by microcrystalline to drusiform calcite (A). 

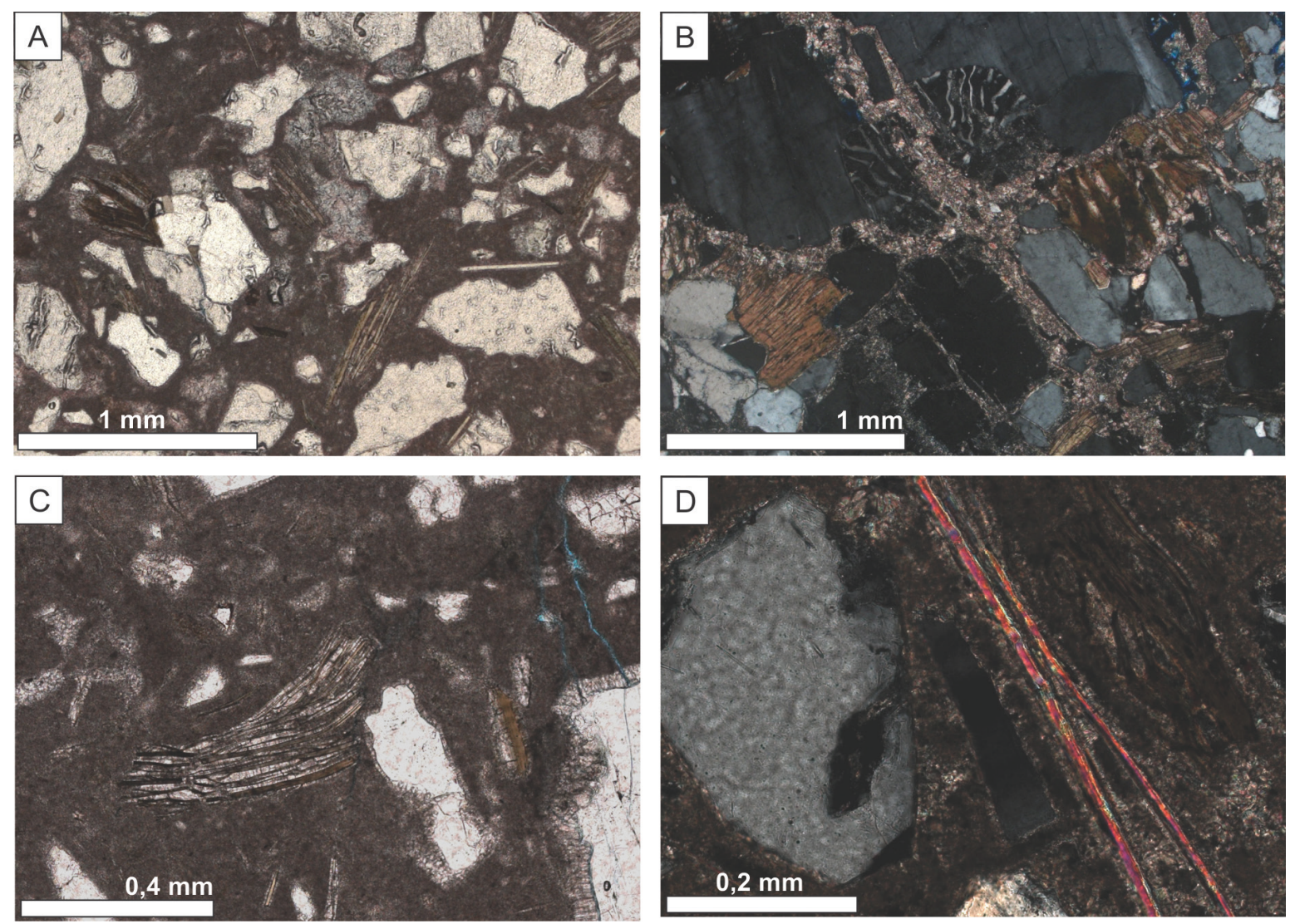

Figura 10. Feições micromorfológicas preponderantes nos calcretes da Bacia de Itaboraí. A) calcita criptocristalina cimentando e deslocando os grãos detríticos. Biotitas expandidas por precipitação de calcita entre as clivagens. Polarizadores descruzados (//P); B) Grãos fraturados pela intensa precipitação de calcita. Polarizadores cruzados (XP); C) Gretas circungranulares em torno de grãos detríticos preenchidas por calcita microcristalina a fibrosa e biotita expandida por precipitação e calcita fibrosa entre as clivagens, (//P); D) Muscovita expandida por precipitação de calcita criptocristalina e microcristalina entre as clivagens, (XP).

Figure 10. Main features in studied calcretes. A) Cryptocrystalline calcite cementing and displacing grains. Biotites expanded by calcite precipitation between cleavages. Uncrossed polarizers (//P); B) Grain fracturing due to calcite precipitation. Crossed polarizers (XP); C) Circumgranular cracks around grains filled by microcrystalline to fibrous calcite and biotite expansion due to fibrous calcite precipitation between cleavages, $(/ / P)$; D) Muscovite expansion due to cryptocrystalline and microcrystalline calcite precipitation between cleavages, (XP).

2010).É sugerido que a precipitação de carbonato em condições pedogenéticas resulte da evaporação, evapotranspiração e do decréscimo na pressão de $\mathrm{CO}_{2}$ (Wright \& Tucker, 1991). A significância de diversos organismos, como plantas, fungos e bactérias, para a formação de calcretes pedogenéticos foi estabelecida por diversos autores (Klappa, 1978; Wright \& Tucker, 1991; Braissant et al., 2003; Dixon \& McLaren, 2009). 0 aporte eólico, especialmente em ambientes desérticos, também é considerado por diversos autores como fonte do carbonato de cálcio que constitui dos calcretes (Gile et al., 1966; Goudie, 1978, 1983; Bachman \& Machette, 1977; Achyutan, 2003).

$\mathrm{Na}$ bacia, foram identificados calcretes pedogenéticos representativos de diferentes estágios de desenvolvimento, classificados segundo estágios morfogenéticos a exemplo de Machette (1985) e Alonso-Zarza (2003).

Os calcretes pulverulentos são os menos desenvolvidos dentre os estudados. Por suas carac- terísticas morfológicas, em especial pela relativamente baixa concentração de carbonato que contém, essa fácies foi relacionada aos primeiros estágios do desenvolvimento dos calcretes, Estágio II de Machette (1985) e Estágio 3 de Alonso-Zarza (2003).

Alguns dos calcretes nodulares descritos são constituídos quase que completamente por nódulos carbonáticos coalescidos. Outros, de forma semelhante aos calcretes pulverulentos, ainda apresentam significativa preservação do material argiloso pedogenético entre os nódulos. Wieder \& Yaalon (1982) afirmam que a forma de ocorrência dos nódulos carbonáticos é função da interferência entre diversos fatores, como a ocorrência de argilominerais, estabilidade da estrutura do solo, textura do solo e ocorrência de microorganismos. Estes fatores seriam responsáveis tanto pelo tamanho cristalino da calcita como pelo tamanho dos nódulos e disseminação destes. Os calcretes nodulares foram interpretados como correspondentes 
aos estágios de desenvolvimento III de Machette (1985) e 3 de Alonso-Zarza (2003).

A fácies de calcretes maciços, que foi associada a estágios mais avançados de evolução do que
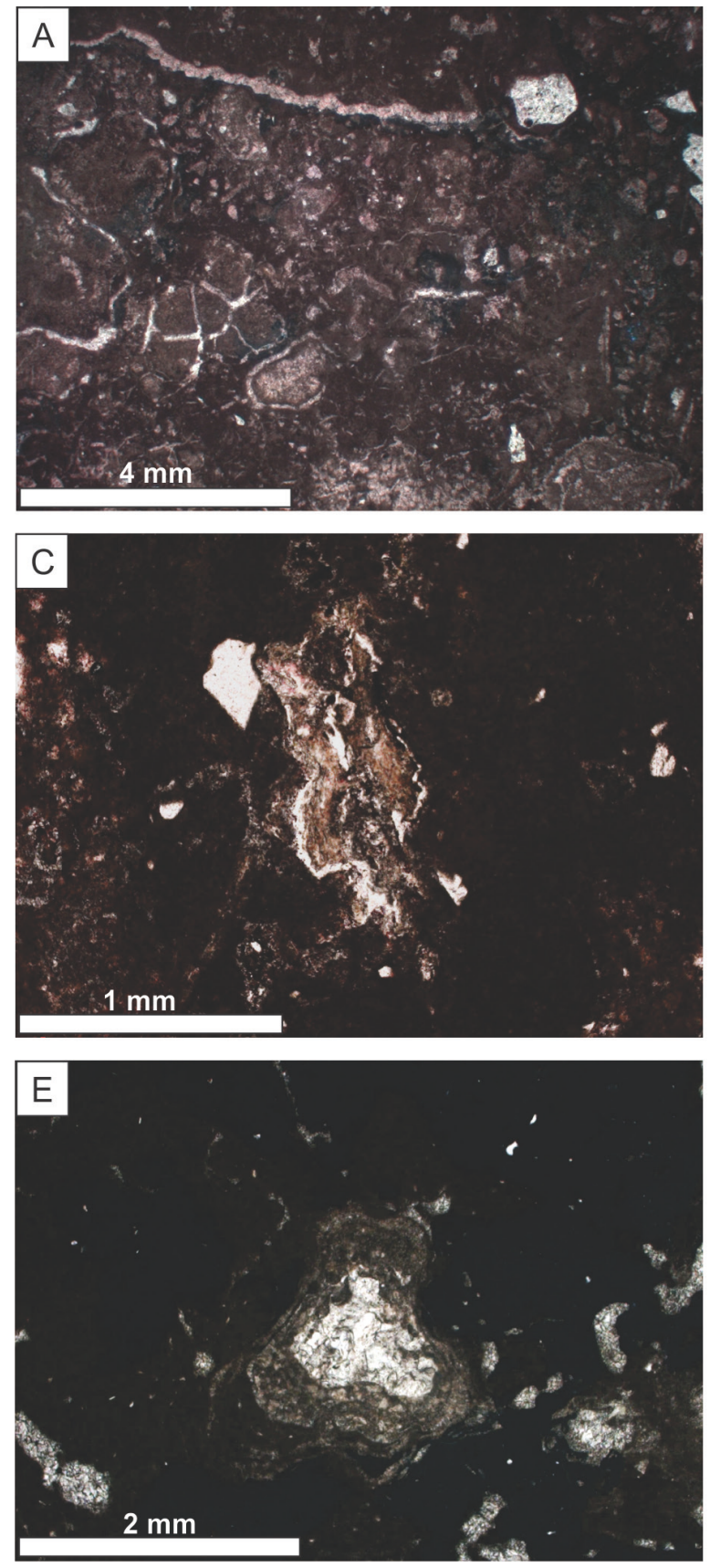

as pulverulentas e nodulares, representa o início do desenvolvimento de uma crosta endurecida (hardpan). A estrutura maciça é originada quando a precipitação de carbonato é mais abundante e os
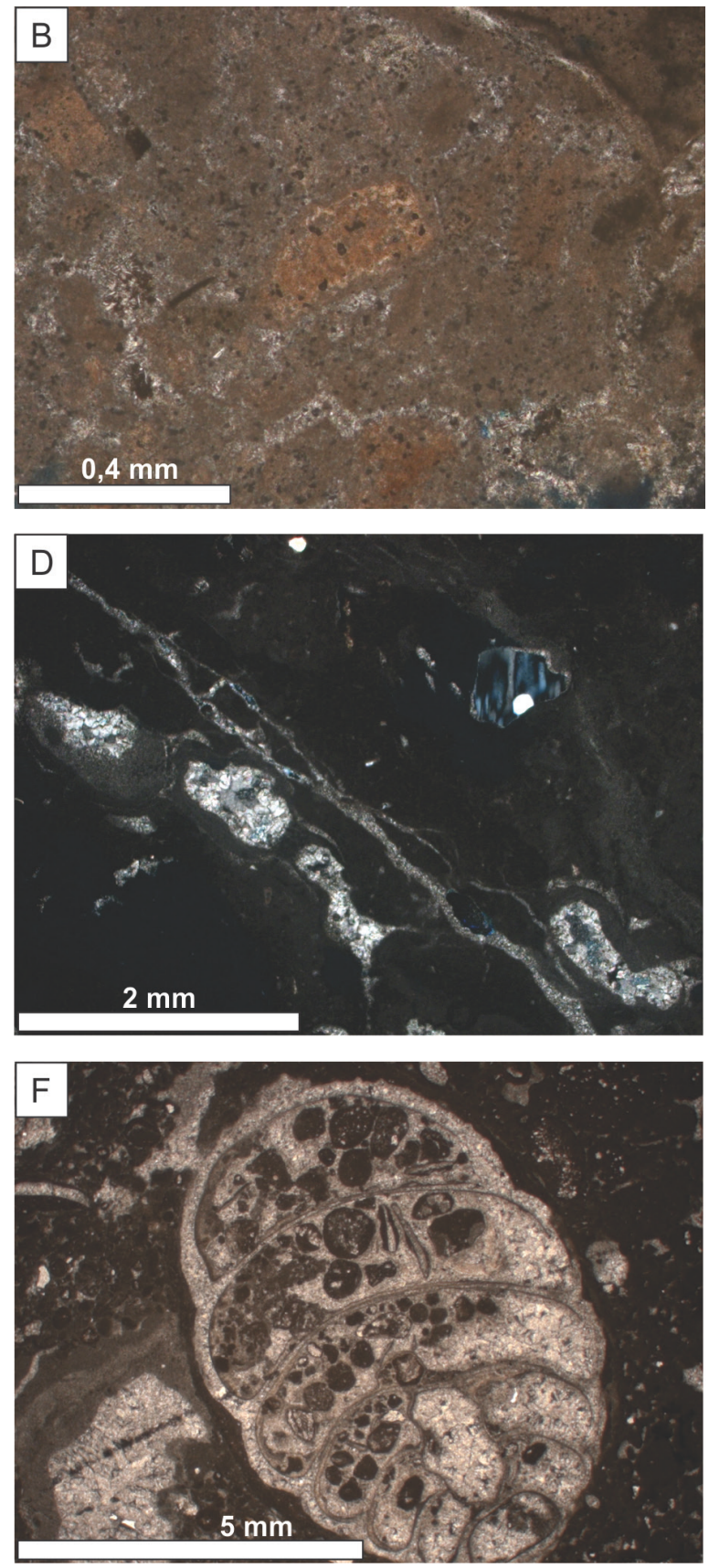

Figura 11. Características micromorfológicas de calcretes estudados. A) Calcita criptocristalina, constituindo nódulos e agregados formados por nódulos coalescidos, com gretas irregulares, poligonais e circungranulares preenchidas por calcita de cristalinidade mais grossa. Grãos detríticos esparsos "flutuam" na calcita criptocristalina. (//P); B) Pirita framboidal disseminada e substituição de nódulos de calcita criptocristalina por óxidos-hidróxidos de ferro, (//P); C) Preenchimento de fraturas por argilominerais infiltrados (//P); D) Greta de dissecação sub-horizontal, paralela ao eixo mais alongado de moldes de raízes, com orientação sub-horizontal, (XP); E) Encrustações pendulares em rizocreção (alternância entre calcita criptocristalina e microcristalina), (XP); F) Concha de gastrópode com morfologia preservada, substituída por calcita microcristalina e preenchida por grãos carbonáticos peloidais e calcita microcristalina, (//P).

Figure 11. Micromorphological features of the calcretes. A) Cryptocrystalline calcite forming nodules and aggregates of coalesced nodules, cut by cracks showing several geometries (irregular, polygonal, circumgranular), filled by a coarser crystalline calcite. Grains float within cryptocrystalline calcite, $(/ / P)$; B) Disseminated framboidal pyrite and cryptocrystalline calcite nodules replaced by iron oxide-hydroxides, (//P); C) Infiltrated clay minerals infilling fractures, (//P); D) Sub-horizontal desiccation cracks parallel to the major elongation of root molds, (XP); E) Pendular encrustations around a rhizolith, (XP). Gastropod shell with preserved shape, replaced by microcrystalline calcite and filled with peloidal carbonate grains and microcrystalline calcite, $(/ / P)$. (F) Well-preserved gastropod shell replaced by microcrystalline calcite and filled by carbonate peloids and microcrystalline calcite. 
nódulos coalescem, gerando lentes e camadas contínuas de carbonato. Por esse motivo, é interpretada como resultado de períodos mais longos de exposição sem sedimentação clástica significativa. Foram atribuídos aos estágios III-IV de Machette (1985) e 5A de Alonso-Zarza (2003).

Estrutura laminar mal desenvolvida, ondulatória e de espessura centimétrica, fraturas de contração planas e abundância de rizólitos são feições classicamente relacionadas aos calcretes placosos (Bachman \& Machette, 1977; Machette, 1985; Alonso-Zarza, 2003; Wright, 2007; Alonso-Zarza \& Wright, 2010), cujo estágio de desenvolvimento corresponde ao V de Machete (1985) e 4 de Alonso-Zarza (2003).

Em alguns dos calcretes placosos e laminares incipientes é possível observar com clareza os contornos de nódulos, que coalesceram e originaram os agregados maciços. Isto está em concordância com interpretação corrente de sua gênese (Bachman \& Machette, 1977; Wright et al., 1995; Alonso-Zarza \& Wright, 2010) pela formação de um denso horizonte, por coalescência de nódulos, através do qual a água e sistemas de raízes não conseguem facilmente penetrar. Precipitação de calcita a partir da água que fluiu lateralmente sobre a superfície superior desses densos horizontes origina as laminações milimétricas e centimétricas. Este processo também muda a morfologia do sistema de raízes, gerando uma rede de estruturas tubulares planares sub-horizontais. A participação da atividade das raízes na formação dos calcretes laminares incipientes parece ter sido mais intensa do que nos placosos, a julgar pela maior quantidade de rizólitos observada.

Os calcretes laminares incipientes são interpretados como o Estágio IV de Machette (1985) e 4 de Alonso-Zarza (2003). No entanto, a porção superior do intervalo laminar, que apresenta o desenvolvimento incipiente de pisolitos, foi considerada representativa do Estágio VI de Machette (1985) e 5A de Alonso-Zarza (2003). Esta porção superior do intervalo denota a ocorrência de brechação in situ, seguida de envelopamento e cimentação dos fragmentos (Machette, 1985).

Essa notável variação de estágios de desenvolvimento dentro de um mesmo intervalo de calcretes laminares sugere a possibilidade destes constituírem "microperfis" ou "subperfis" de calcretes, que parecem registrar múltiplas fases de precipitação, erosão e exposição (Wright, 2007; Alonso-Zarza \& Silva, 2002), que podem formar unidades de até $2 \mathrm{~m}$ de espessura (Alonso-Zarza \& Silva, 2002).
A associação da estrutura laminar incipiente com estruturas nodulares, brechadas e pisolíticas, que ocorrem de forma subordinada, evidenciam e corroboram esse caráter poligenético dos calcretes laminares, que é reconhecido por diversos autores (Machette, 1985; Aloso-Zarza, 2003; Sacristán-Horcajada et al., 2016).

A exposição das crostas carbonáticas, maciças ou laminadas, a processos intempéricos, como a ação de plantas, fraturamento por contração, dissolução parcial e colapso, dentre outros, leva à sua brechação e à destruição parcial e superficial dos perfis (Esteban \& Klappa, 1983; Alonso-Zarza, 2003). As fraturas geradas por esses processos podem ser preenchidas por sedimentos clásticos e recimentadas por novas fases de precipitação de calcita, originando os calcretes brechados.

Este processo de "brechação" e recimentação ocorre em situações em que tanto a taxa de sedimentação como a taxa de erosão são baixas (Alonso-Zarza, 2003; Sacristán-Horcajada et al., 2016), o que provavelmente é relacionado a ciclos tectônicos e climáticos (Machette, 1985). Soerguimento relativo do embasamento poderia aumentar a taxa de sedimentação, enquanto chuvas torrenciais sazonais, por exemplo, promoveriam alto escoamento superficial (runoff flows) e erosão dos perfis (Bachman \& Machette, 1977).

0 processo de fraturamento registrado nos calcretes brechados possivelmente resultou do crescimento penetrativo de raízes (Klappa, 1980b; Košir, 2004), de ciclos de exposição (contração por ressecamento) e da atividade organismos.

Assim como os calcretes laminares, os calcretes brechados apresentam caráter poligenético, sendo associados a estágios avançados de desenvolvimento de calcretes pedogenéticos, correspondendo aos estágios VI de Machette (1985) e 5A de Alonso-Zarza (2003).

Rizólitos foram identificados nos calcretes maciços, placosos, laminares e brechados, sob diferentes formas de ocorrência: 1) moldes tubulares de raízes (sensu Klappa, 1980a), que são a ocorrência dominante, em geral preenchidos por mosaicos de calcita ou calcita drusiforme; 2) rizocreções (sensu Klappa, 1980a), que ocorrem como acumulações pedodiagenéticas de calcita criptocristalina ou microcristalina em torno de moldes, originadas durante a vida ou logo após a morte da planta; e, de forma mais restrita, como permineralização de tecidos (Košir, 2004), configuradas como impregnação do tecido celular, mas sem petrificação do material intracelular.

Em alguns desses calcretes, os moldes tubulares de raízes apresentam preenchimento geopetal, 
parte por silte vadoso, parte por calcita microcristalina ou drusiforme. Também é verificada a presença localizada de argilominerais infiltrados nesses moldes, em cavidades vugulares e em fraturas. Essas feições indicam oscilações no nível freático, provavelmente relacionadas a ciclos climáticos (sazonalidade).

A ocorrência de pirita em meio aos agregados de argilominerais indica a vigência de condições pedogenéticas estagnantes, com oxigênio exaurido, em que minerais que contêm ferro são degradados e liberam ferro no estado reduzido, que se liga com íons sulfeto. Estas condições poderiam ser propiciadas tanto pela elevação do nível freático como pela acumulação de águas superficiais em terrenos rebaixados por períodos sazonais. Essas, no entanto, não implicam necessariamente em baixos pHs no solo, já que a percolação de fluidos em regiões de ocorrência de carbonatos pode tornar o ambiente alcalino (Retallack, 2001).

Os momentos de estagnação também proporcionariam a remobilização do ferro, gerando as feições de mosqueamento observadas em escala macro e microscópica. A remobilização do ferro ocorre devido a mudanças de Eh ocasionadas pela oscilação sazonal do nível d'água (Freytet \& Plaziat, 1982; Wright \& Platt, 1995; Freytet \& Verrecchia, 2002).

Durante a exposição às condições subaéreas em ambiente vadoso, diversos processos atuaram sobre o carbonato de cálcio precipitado no solo: contração do material, gerando gretas; infiltração mecânica de argilas e de silte vadoso em cavidades; substituição de constituintes por óxidos-hidróxidos de ferro. 0 posterior reposicionamento dos depósitos na zona freática propiciou o preenchimento de todos os tipos de vazios (gretas, moldes de raízes, cavidades de dissolução) por calcita de cristalinidade mais grossa e a remobilização de óxidos-hidróxidos de ferro.

A sazonalidade interpretada a partir das feições descritas é típica de ambientes áridos a semiáridos e muito favorável ao desenvolvimento de calcretes pedogenéticos, que são classicamente relacionados estes climas (Gile et al., 1966; Esteban \& Klappa, 1983; Wright, 2007). No entanto, há diversos exemplos de calcretes que representam períodos relativamente mais úmidos dentro de climas áridos e semiáridos (Alonso-Zarza, 2003).

As conchas de gastrópodes, fraturadas ou inteiras, que se encontram preservadas em meio à calcita criptocristalina, provavelmente pertenceram a organismos que habitavam no substrato. Esta interpretação está em consonância com a informação de que os gastrópodes da Bacia de Itabo- raí são majoritariamente pulmonados, terrestres (Ferreira \& Coelho, 1971; Palma \& Brito, 1974; Sant'Anna et al., 2004).

Nota-se predominância de microfábrica alfa (Wright \& Tucker, 1991) nos calcretes pedogenéticos descritos, que apresentam ausência de estruturas biogênicas, sendo os rizólitos o único registro de atividade biológica durante sua formação. Essa constatação está em consonância com o fato de terem sido identificadas feições características do reposicionamento desses calcretes na zona freática. Os processos freáticos possivelmente foram os últimos a atuar nesses materiais, modificando feições pedogenéticas anteriores. Modificações de paleossolos e calcretes vadosos por processos freáticos, além de atividade hidrotermal ou metamorfismo, parecem ser comuns no registro geológico (Retallack, 2001; Fernandes, 2010).

Os sedimentos arenosos a conglomeráticos, texturalmente imaturos, que serviram de substrato para a acumulação carbonática que deu origem aos calcretes foram interpretados como aluviais. É muito comum o desenvolvimento de calcretes em sistemas aluviais, havendo diversos casos disponíveis para estudo na literatura (Sehgal \& Stoops, 1972; Kaemmerer \& Revel, 1991; Alonso-Zarza et al., 1998; Nash \& Smith, 1998; Khadkikar et al., 2000; Sacristán-Horcajada et al., 2016).

0 intervalo basal do testemunho (Fig. 6) consiste em um perfil bem desenvolvido de calcretes pedogenéticos (profundidade ente 35,80 e 29,30 $\mathrm{m})$, disposto diretamente sobre o embasamento. Neste intervalo, é observada uma sucessão formada por calcretes pulverulentos, nodulares, maciços, placosos, brechados e laminares incipientes, que evidencia um período de estabilidade tectônica, com baixo influxo de detritos e em vigência de clima árido a semiárido ainda nos momentos iniciais de desenvolvimento da Bacia. Simbolizam a evolução do estágio II ao VI de Machette (1985) e 3 a 5 A de Alonso-Zarza (2003).

Os calcretes pedogenéticos sotopostos a este intervalo não apresentam estágios de desenvolvimento avançados e ocorrem com espessuras menores do que a observada no intervalo basal. Além disso, em profundidades mais rasas que $29,30 \mathrm{~m}$, os calcretes se encontram intercalados com travertinos (que podem estar afetados por pedogênese). A deposição dos travertinos é intimamente controlada pela movimentação de falhas ativas (Sibson, 1987; Hancock et al., 1999; Faccenna et al., 2008) e por ciclos paleoclimáticos, sendo favorecida em períodos quentes e úmidos (Minissale et al., 2002; Dilsiz et al., 2004; Faccenna et al., 2008; Uysal et al., 2009). A este tipo de clima é atribuído um au- 
mento da disponibilidade de água meteórica, que promove melhor circulação hidrotermal (Sturchio et al., 1993; Rihs et al., 2000; Minissale et al., 2002)

Desta forma, o desenvolvimento dos calcretes pedogenéticos mais novos do que os que constituem a referida sucessão basal foi perturbado e interrompido por movimentações tectônicas de maior frequência, associadas à circulação hidrotermal, preferencialmente em climas úmidos, originando os travertinos, e à entrada de sedimentos aluviais. A entrada desses sedimentos na bacia, condicionada a um relevo acentuado na área fonte, pode ter ocorrido tanto em períodos de clima árido como de clima úmido (Ferrari, 2001; Alonso-Zarza et al., 1993). No entanto, a geração dos calcretes pedogenéticos nesses sedimentos marcam períodos de clima árido a semiárido em condições de estabilidade.

Essa análise evidencia a importância das movimentações tectônicas, da circulação hidrotermal, dos eventos de sedimentação clástica episódica e dos processos pedogenéticos na geração das sucessões de fácies observadas nos depósitos basais da Bacia de Itaboraí.

\section{Conclusões}

Na Bacia de Itaboraí, foram descritos calcretes que apresentam uma variedade de feições macromorfológicas e micromorfológicas típicas de ambientes vadosos e que se formaram durante períodos de clima árido a semiárido, em vigência de estabilidade tectônica.

Estes calcretes pedogenéticos foram separados por fácies, que apresentam diferentes características macromorfológicas dominantes e foram associadas a estágios de desenvolvimento distintos.

A introdução de carbonato de cálcio comumente ocorreu em sedimentos imaturos texturalmente, interpretados como aluviais. Nos calcretes pulverulentos e em alguns dos nodulares foi possível inferir o desenvolvimento de solos antes da precipitação dos calcretes nesses materiais, devido à presença de abundantes argilominerais pedogenéticos entre os grãos detríticos. A matriz pedogenética (argilominerais e carbonato) presente nestes depósitos representa estágios iniciais de introdução de carbonato de cálcio em perfis de solo. Calcretes com maiores proporções de carbonato de cálcio, abundância de marcas de raízes e estruturas laminares ou brechadas correspondem a estágios mais avançados de desenvolvimento (fácies maciça, placosa, laminar incipiente e brechada).

As principais feições micromorfológicas vado- sas descritas nos calcretes pedogenéticos incluem: abundante calcita criptocristalina cimentando e deslocando grãos detríticos, gretas de contração, rizólitos, grãos corroídos e fraturados, micas expandidas e preenchimento parcial de cavidades por silte vadoso ou por argilas infiltradas.

As feições de mosqueamento (indicativo de remobilização do ferro), a presença pirita framboidal (típica de condições redutoras) e o preenchimento de cavidades por calcita de cristalinidade grossa indicam que os calcretes gerados na zona vadosa foram reposicionados na zona freática. Os processos freáticos que aturam nos calcretes, possivelmente, mascararam feições típicas da microfábrica beta (Wright \& Tucker, 1991), fazendo com que haja preponderância da microfábrica alfa nesses calcretes.

No intervalo basal do testemunho de sondagem, ocorre uma sucessão de calcretes pedogenéticos bem desenvolvidos, disposta sobre o embasamento. Acima desta sucessão, os calcretes pedogenéticos ocorrem intercalados com travertinos (afetados ou não por pedogênese), calcretes afetados pela ação de fluidos hidrotermais e calcretes freáticos, e não apresentam estágios de desenvolvimento avançado. Pelo fato desses diferentes litotipos serem gerados em condições climáticas e/ou tectônicas distintas, fica evidenciada a existência de ciclos tectônicos-climáticos durante a evolução da bacia.

A alternância entre períodos de estabilidade e instabilidade tectônica, estes caracterizados por movimentação das falhas e maior atividade hidrotermal, favoreceu a formação hora de calcretes, hora de travertinos. Durante períodos tectonicamente ativos e de clima quente e úmido, litologias do embasamento, depósitos aluviais e calcretes sobre eles desenvolvidos foram modificados pela atividade hidrotermal, e travertinos se formaram. Em períodos de estabilidade e exposição, e em vigência de clima árido a semiárido, os depósitos aluviais e hidrotermais foram intensamente modificados por processos pedogenéticos.

Dentro dos ciclos de desenvolvimento de calcretes é possível identificar "subciclos" de erosão e de precipitação de calcita que foram condicionados, de forma geral, por condições ambientais e pelo influxo de detritos, e que são perceptíveis pela superposição de diferentes tipos macromorfológicos, não necessariamente na sequência genética prevista para o desenvolvimento dos perfis de calcretes, determinada na literatura (Gile et al., 1966; Machette, 1985; Alonso-Zarza, 2003).

A existência dos ciclos e subciclos interpretados a partir das intercalações descritas indica uma 
importante dinâmica, envolvendo o clima, o tectonismo e o hidrotermalismo durante a evolução inicial da Bacia de Itaboraí.

Agradecimentos. À CAPES, pela bolsa de apoio ao desenvolvimento do projeto de mestrado no Programa de Pós-Graduação em Geologia da UFRJ e à Prefeitura de Itaboraí na pessoa de Luis Otávio Rezende Castro, pelo apoio aos trabalhos de campo.

\section{Referências}

Achyuthan, H. 2003. Petrologic analysis and geochemistry of the Late Neogene-Early Quaternary hardpan calcretes of Western Rajasthan, India. Quaternary International, 106: 3-10.

Adler, P. B. 2016. Calcretes e Travertinos da Bacia de Itaboraí, estado do Rio de Janeiro. Rio de Janeiro, 228p. Dissertação de Mestrado, Programa de Pós-graduação em Geologia, Universidade Federal do Rio de Janeiro.

Alonso-Zarza, A.M. 1999. Initial stages of laminar calcrete formation by roots: examples from the Neogene of central Spain. Sedimentary Geology, 126(1-4): 177-191.

Alonso-Zarza, A.M. 2003. Palaeoenvironmental significance of palustrine carbonates and calcretes in the geological record. Earth-Science Reviews, 60: 261298.

Alonso-Zarza, A.M. \& Silva, P.G. 2002. Quaternary laminar calcretes with bee nests: evidences of small-scale climatic fluctuations, Eastern Canary Islands, Spain. Palaeogeography, Palaeoclimatology, Palaeoecology, 178(1): 119-135.

Alonso-Zarza, A.M. \& Wright, V. P. 2010. Calcretes. Developments in Sedimentology, 61: 225-267.

Alonso-Zarza, A.M., Silva, P.G., Goy, J.L. \& Zazo, C. 1998. Fan-surface dynamics and biogenic calcrete development: interactions during ultimate phases of fan evolution in the semiarid SE Spain (Murcia). Geomorphology, 24(2): 147-167.

Bachman, G.O. \& Machette, M.N. 1977. Calcic soils and calcretes in the southwestern United States. US Geological Survey, Open-file report, 77-794, 163p.

Beltrão, M.C.M.C., Rodrigues Francisco, B.H., Perez, R. A. R., Bezerra, F.O.S., Carvalho, B., Caniné, J.M.M. \& Koatz, G.D. 2001. O Parque Paleontológico de São José de Itaboraí (Rio de Janeiro) e seu Entorno. Revista Brasileira de Paleontologia, 2: 53-55.

Bergqvist, L.P., Moreira, A.L. \& Pinto, D. R. 2005. Bacia de São José de Itaboraí: 75 anos de história e ciência. Rio de Janeiro, Serviço Geológico do Brasil - CPRM, 84p.

Braissant, O.; Cailleau, G.; Dupraz, C. \& Verrecchia, E.P. 2003. Bacterially induced mineralization of calcium carbonate in terrestrial environments: the role of exopolysaccharides and amino acids. Journal of Sedimentary Research, 73(3): 485-490.

Brewer, R. 1976. Fabric and mineral analysis of soils. New York, Krieger, $482 \mathrm{p}$.

Brito, I.M. 1989. Geologia e paleontologia da bacia calcá- ria de São José de Itaboraí, estado do Rio de Janeiro, Brasil. Anuário do Instituto de Geociências, 12: 56-64.

Brito, I.M., Frankie, H.F.C.M. \& Campos, D.A. 1972. Geologia e Petrografia de São José do Itaboraí, RJ. Anais da Academia Brasileira de Ciências, 42(2): 225-234.

Buczynski, C. \& Chafetz, H.S. 1987. Siliciclastic grain breakage and displacement due to carbonate crystal growth: an example from the Lueders Formation (Permian) of north-central Texas, USA. Sedimentology, 34(5): 837-843.

Bullock, P., Fedoroff, N., Jongerius, A., Stoops, G. \& Tursina, T., 1985. Handbook for Soil Thin Section Description. Wolverhampton, Waine Research Publications, $152 \mathrm{p}$.

Dal' Bó, P.F.F., Basilici, G., Angelica, R.S. \& Ladeira, F.S.B. 2009. Paleoclimatic interpretations from pedogenic calcretes in a Maastrichtian semi-arid eolian sand-sheet palaeoenvironment: Marília Formation (Bauru Basin, southeastern Brazil). Cretaceous Research, 30(3): 659-675.

De Castro, S.S. 2008. Micromorfologia de Solos. Campinas/Goiânia, UNICAMP/UFG, 135p.

Dilsiz, C., Marques, J.M. \& Carreira, P.M.M. 2004. The impact of hydrological changes on travertine deposits related to thermal springs in the Pamukkale area (SW Turkey). Environmental Geology, 45(6): 808817.

Dixon, J.C. \& McLaren, S.J. 2009. Duricrusts. In: Parsons, A.J., Abrahams, A. D. (Eds.). Geomorphology of desert environments. Colchester, Springer Netherlands, $\mathrm{p}$. 123-151.

Esteban, M. \& Klappa, C.F. 1983. Subaerial exposure environment. In: Scholle, P.A., Bebout, D.G., Moore, C.H. (Eds.), Carbonate Depositional Environments: AAPG Memoir 33. Tulsa, Oklahoma, American Association of Petroleum Geologists, p. 1-54.

Faccenna, C., Soligo, M., Billi, A., De Filippis, L., Funiciello, R., Rossetti, C. \& Tuccimei, P. 2008. Late Pleistocene depositional cycles of the Lapis Tiburtinus travertine (Tivoli, Central Italy): possible influence of climate and fault activity. Global and Planetary Change, 63(4): 299-308.

Fedoroff, N. 1997. Clay illuviation in Red Mediterranean soils. Catena, 28(3): 171-189.

Fedoroff, N., Courty, M.A. \& Guo, Z. 2010. Palaeosoils and relict soils. In: Stoops, G., Marcelino, V., Mees, F. (Eds). Interpretation of Micromorphological Features of Soils and Regoliths. Oxford, Elsevier, p. 623-662.

Fernandes, L.A. 2010. Calcretes e registros de paleossolos em depósitos continentais neocretáceos (Bacia Bauru, Formação Marília). Revista Brasileira de Geociências, 40(1): 19-35.

Ferrari, A.L. 2001. Evolução tectônica do Graben da Guanabara. São Paulo, 412p. Tese de Doutorado, Programa de Pós-Graduação em Geologia Sedimentar, Instituto de Geociências, Universidade de São Paulo.

Ferreira, C.S. \& Coelho, A.C.S. 1971. Novos gastrópodes pulmonados da Bacia Calcária de São José de Itaboraí, RJ, Brasil. Geocronologia. Anais da Academia Brasileira de Ciências, 43(Suplemento): 463-472.

Fitzpatrick, E.A. 1984. The micromorphology of soils. 
In: Fitzpatrick, E.A. Micromorphology of soils. London, Springer Netherlands, p. 331-357.

Folk, R.L. \& Chafetz, H.S. 1983. Pisoliths (pisoids) in Quaternary travertines of Tivoli, Italy. In: Peryt, T.M. (Ed.). Coated Grains. Berlin, Springer, p. 474-487.

Freytet, P. \& Plaziat, J.C. 1982. Continental carbonate sedimentation and pedogenesis - Late Cretaceous and Early Tertiary of southern France. Contributions to Sedimentology, 12: 213p.

Freytet, P. \& Verrecchia, E.P. 2002. Lacustrine and palustrine carbonate petrography: an overview. Journal of Paleolimnology, 27(2): 221-237.

Gile, L.H., Peterson, F.F., \& Grossman, R.B. 1965. The K horizon: a master horizon of carbonate accumulation. Soil Science, 97: 74-82.

Gile, L.H., Peterson, F.F. \& Grossman, R.B. 1966. Morphological and genetic sequences of carbonate accumulation in desert soils. Soil Science, 101: 347-360.

Goudie, A.S. 1973. Duricrusts in Tropical and Subtropical Landscapes. Oxford, UK, Clarendon, $174 \mathrm{p}$.

Goudie, A.S. 1978. Dust storms and their geomorphological implications. Journal of Arid Environments, 1: 291-310.

Goudie, A.S. 1983. Calcrete. In: Goudie, A.S. \& Pye, K. (Eds.). Chemical Sediments and Geomorphology. London, Academic Press, p. 93 - 131.

Guo, L. \& Riding, R. 1998. Hot-spring travertine facies and sequences, Late Pleistocene, Rapolano Terme, Italy. Sedimentology, 45: 163-180.

Hallsworth, C.R. \& Knox, R.W.O'B. 1999. BGS Rock Classification Scheme, Volume 3: Classification of sediments and sedimentary rocks. British Geological Survey Research Report, RR: 99-03.

Hancock, P.L.; Chalmers, R.M.L.; Altunel, E. \& Cakir, Z. 1999. Travitonics: using travertines in active fault studies. Journal of Structural Geology, 21(8): 903916.

Kaemmerer, M. \& Revel, J.C. 1991. Calcium carbonate accumulation in deep strata and calcrete in Quaternary alluvial formations of Morocco. Geoderma, 48(1): 43-57.

Khadkikar, A.S., Chamyal, L.S. \& Ramesh, R. 2000. The character and genesis of calcrete in Late Quaternary alluvial deposits, Gujarat, western India, and its bearing on the interpretation of ancient climates. Palaeogeography, Palaeoclimatology, Palaeoecology, 162(3): 239-261.

Klappa, C.F. 1978. Biolithogenesis of Microcodium: elucidation. Sedimentology, 25(4): 489-522.

Klappa, C.F. 1980a. Rhizoliths in terrestrial carbonates: classification, recognition, genesis and significance. Sedimentology, 27: 613-629.

Klappa, C.F. 1980b. Brecciation textures and tepee structures in Quaternary calcrete (caliche) profiles from eastern Spain: the plant factor in their formation. Geological Journal, 15(2): 81-89.

Klein, V.C. \& Bergqvist, L.P. 2002. Excursão à bacia de São José de Itaboraí, Rio de Janeiro. Arquivos do $\mathrm{Mu}$ seu Nacional, 60(3): 245-256.

Klein, V.C. \& Valença, J.G. 1984. Estruturas almofadadas em derrame ankaramítico na bacia de São José de
Itaboraí, Rio de Janeiro. In: CONGRESSO BRASILEIRO DE GEOLOGIA, 33., 1984, Rio de Janeiro. Anais... Rio de Janeiro, SBG, v. 9, p. 4335-4339.

Košir, A. 2004. Microcodium revisited: root calcification products of terrestrial plants on carbonate-rich substrates. Journal of Sedimentary Research, 74(6): 845-857.

Kubiena, W.L. Micropedology. 1938. Ames, Collegiate Press, 242p.

Leinz, V. 1938. Os calcários de São José, Niterói, Estado do Rio. Mineração e Metalurgia, 3(15): 153-155.

Lima, M.R. \& Cunha, F.L.S. 1986. Análise palinologica de um nível linhítico de bacia de São Jose de Itaborai, Terciário do Estado de Rio de Janeiro, Brasil. Anais da Academia Brasileira de Ciências, 58(4): 579-588.

Luna J.L. 2012. Perfis resistivo e de indução em poços delgados: UFRJ-1-RJ e ITAB-1-RJ. Rio de Janeiro, 91p. Dissertação de Mestrado, Programa de Pós-graduação em Geologia, Universidade Federal do Rio de Janeiro.

Luna J.L., Rocha, P.F., Fernandes, C.E., Perosi, F.A., Abreu, C.J., Silva, E.A., Siqueira, M. \& Lopes, R.T. 2012. Teste de Ferramenta de Perfilagem Elétrica em Poço Delgado na Bacia de Săo José de Itaboraí, RJ. In: SIMPÓSIO BRASILEIRO DE GEOFÍSICA, V, Salvador. Resumo expandido... Salvador, SBGf, 4p.

Machette, M.N. 1985. Calcic soils of the southwestern United States. Geological Society of America Special Papers, 203: 1-22.

Medeiros, R.A \& Bergqvist, L.P. 1999. Paleocene of the São José do Itaboraí Basin, Rio de Janeiro, Brazil: Lithostratigraphy and Biostratigraphy. Acta Geologica Leopoldensia, 22(48): 3-22.

Minissale, A., Kerrick, D.M., Magro, G., Murrell, M.T., Paladini, M., Rihs, S., Sturchio, N.C., Tassi, F. \& Vaselli, O. 2002. Geochemistry of Quaternary travertines in the region north of Rome (Italy): structural, hydrologic and paleoclimatic implications. Earth and Planetary Science Letters, 203(2): 709-728.

Mota, C.E., Geraldes, M.C., Jourdan, F., Bergamaschi, S. \& Motoki, A. 2015. Idade Ar/Ar do Ankaramito de São José de Itaboraí, Rio de Janeiro: Considerações acerca do magmatismo Pós-Cretáceo. In: SIMPÓSIO NACIONAL DE ESTUDOS TECTÔNICOS, XV, INTERNATIONAL SYMPOSIUM ON TECTONICS, IX, 2015, Vitória. Resumos expandidos...Vitória, p. 646-649.

Munsell, 1991. The Geological Society of America Rock-Color Chart: with genuine Munsell color chips. Boulder, The Geological Society of America, 8p.

Nash, D.J. \& Smith, R.F. 1998. Multiple calcrete profiles in the Tabernas Basin, southeast Spain: their origins and geomorphic implications. Earth Surface Processes and Landforms, 23(11): 1009-1029.

Netterberg, F. 1969. The interpretation of some basic calcrete types. The South African Archaeological Bulletin, 24(95/96): 117-122.

Palma, J.M.C. \& Brito, I.M. 1974. Paleontologia e estratigrafia da bacia de São José do Itaboraí, Estado do Rio de Janeiro. Anais da Academia Brasileira de Ciências, 46(3/4): 383-406.

Price, L.I. \& Campos, D.A. 1970. Fósseis pleistocênicos 
no município de Itaboraí, estado do Rio de Janeiro. In: CONGRESSO BRASILEIRO DE GEOLOGIA, 24, Brasília, 1970. Anais... Brasília, SBG, p. 355-358.

Retallack, G.J. 2001. Soils of the past: an introduction to paleopedology. Oxford, Blackwell Science, 404p.

Riccomini, C. 1989. O Rift Continental do Sudeste do Brasil. São Paulo, 256p. Tese de Doutorado, Programa de Pós-Graduação em Geologia Sedimentar, Universidade de São Paulo.

Riccomini, C. \& Rodrigues Francisco, B.H. 1992. Idade potássio-argônio do derrame de ankaramito da bacia de Itaboraí, Rio de Janeiro, Brasil: implicações tectônicas. In: CONGRESSO BRASILEIRO DE GEOLOGIA, 37., 1992, São Paulo, Boletim de Resumos Expandidos.... São Paulo, SBG, p. 469 - 470.

Riccomini, C., Sant'Anna, L.G., Ferrari, A.L. 2004. Evolução geológica do Rift Continental do Sudeste do Brasil. In: Montesso-Neto, V., Bartorelli A., Carneiro, C.D.R., Brito-Neves, B.B (Ed.). Geologia do Continente Sul-Americano: Evolução da obra de Fernando Flávio Marques de Almeida. São Paulo, Editora Beca, p. 283 $-405$.

Rihs, S., Condomines, M. \& Poidevin, J.L. 2000. Long-term behaviour of continental hydrothermal systems: U-series study of hydrothermal carbonates from the French Massif Central (Allier Valley). Geochimica et Cosmochimica Acta, 64(18): 3189-3199.

Rodrigues Francisco, B.H. 1989. Estratigrafia da bacia de São José de Itaboraí. Anuário do Instituto de Geociências, 12: 65-69.

Rodrigues Francisco, B.H. \& Cunha, F.L.S. 1978. Geologia e estratigrafia da bacia de São José, município de Itaboraí, RJ. Anais da Academia Brasileira de Ciências, 50(3): 381-416.

Rodrigues Francisco, B.H., Klein, V.C. \& Cunha, F.L.S. 1982. Novas descobertas de rochas alcalinas na bacia de São José, município de Itaboraí, RJ. Anais da Academia Brasileira de Ciências, 50(8): 263.

Sacristán-Horcajada, S., Arribas, M.E. \& Mas, R. 2016. Pedogenetic Calcretes in Early Syn-Rift Alluvial Systems (Upper Jurassic, West Cameros Basin), Northern Spain. Journal of Sedimentary Research, 86(3): 268-286.

Sant'Anna, L.G. 1999. Geologia, mineralogia e gênese das esmectitas dos depósitos paleogênicos do Rift Continental do Sudeste do Brasil. São Paulo, 293p. Tese de Doutorado, Programa de Pós-Graduação Mineralogia e Petrologia, Instituto de Geociências, Universidade de São Paulo.

Sant'Anna, L.G. \& Riccomini, C. 2001. Cimentação hidrotermal em depósitos sedimentares paleogênicos do

Manuscrito 616

Editores: Ana Maria P. Mizusaki \& Paulo A. Souza
Rift Continental do Sudeste do Brasil: mineralogia e relações tectônicas. Revista Brasileira de Geociências, 31(2): 231 - 240.

Sant'Anna, L.G., Riccomini, C. Rodrigues-Francisco, B. H., Sial, A. N., Carvalho, M.D. \& Moura, C.A.V. 2004. The Paleocene travertine system of the Itaboraí basin, Southeastern Brazil. Journal of South American Earth Sciences, 18(1): 11-25.

Sehgal, J.L. \& Stoops, G. 1972. Pedogenic calcite accumulation in arid and semi-arid regions of the Indo-Gangetic alluvial plain of erstwhile Punjab (India) - Their morphology and origin. Geoderma, 8(1): 5972.

Sibson, R.H. 1987. Earthquake rupturing as a mineralizing agent in hydrothermal systems. Geology, 15(8): 701-704.

Sturchio, N.C., Dunkley, P.N. \& Smith, M. 1993. Climate-driven variations in geothermal activity in the northern Kenya rift valley. Nature, 362: $233-234$.

Tibana, P., Castro, J. C. \& Barrocas, S.L.S. 1984. Bacia de Itaboraí. In: CONGRESSO BRASILEIRO DE GEOLOGIA, XXXIII, 1984, Rio de Janeiro. Anais... Rio de Janeiro, SBG, p. 5309-5316.

Uysal, I.T., Feng, Y.X., Zhao, J.X., Isik, V., Nuriel, P. \& Golding, S.D. 2009. Hydrothermal CO2 degassing in seismically active zones during the late Quaternary. Chemical Geology, 265(3): 442-454.

Watts, N.L. 1980. Quaternary pedogenic calcretes from the Kalahari (southern Africa): mineralogy, genesis and diagenesis. Sedimentology, 27: 661-686.

Wieder, M. \& Yaalon, D.H. 1982. Micromorphological fabrics and developmental stages of carbonate nobular forms related to soil characteristics. Geoderma, 28(3): 203-220.

Wright, V.P., 2007. Calcretes. In: Nash, D. \& McLaren, S. (Eds.). Geochemical Sediments and Landscapes. Oxford, Wiley - Blackwell, p.10-45.

Wright, V.P. \& Platt, N.H. 1995. Seasonal wetland carbonate sequences and dynamic catenas: a re-appraisal of palustrine limestones. Sedimentary Geology, 99(2): 65-71.

Wright, V.P. \& Tucker, M.E. 1991. Calcretes: an introduction. In: Wright, V. P., Tucker, M. E. (Eds), Calcretes. Oxford, Blackwell Scientific Publications, IAS Reprint Series, v. 2, p. 1-22.

Wright, V.P., Platt, N.H., Marriott, S.B. \& Beck, V.H. 1995. A classification of rhizogenic (root-formed) calcretes, with examples from the Upper Jurassic-Lower Cretaceous of Spain and Upper Cretaceous of southern France. Sedimentary Geology, $100(1):$ 143-158. 